\title{
Predicting the impact of spatial heterogeneity on microbially mediated nutrient cycling in the subsurface
}

\author{
Swamini Khurana ${ }^{1}$, Falk Heße ${ }^{2,3}$, Anke Hildebrandt ${ }^{2,4,5}$, and Martin Thullner ${ }^{1}$ \\ ${ }^{1}$ Department of Environmental Microbiology, Helmholtz Centre for Environmental Research - UFZ, \\ Leipzig, 04318, Germany \\ ${ }^{2}$ Department of Computational Hydrosystems, Helmholtz Centre for Environmental Research - UFZ, \\ Leipzig, 04318, Germany \\ ${ }^{3}$ Institute of Earth and Environmental Science-Geoecology, University Potsdam, Potsdam, 14476, Germany \\ ${ }^{4}$ Institute of Geoscience, Friedrich Schiller University Jena, Jena, 07749, Germany \\ ${ }^{5}$ German Centre for Integrative Biodiversity Research, Leipzig, 04103, Germany
}

Correspondence: Swamini Khurana (swamini.khurana@gmail.com)

Received: 25 March 2021 - Discussion started: 18 May 2021

Revised: 13 October 2021 - Accepted: 21 November 2021 - Published: 3 February 2022

\begin{abstract}
The subsurface is a temporally dynamic and spatially heterogeneous compartment of the Earth's critical zone, and biogeochemical transformations taking place in this compartment are crucial for the cycling of nutrients. The impact of spatial heterogeneity on such microbially mediated nutrient cycling is not well known, which imposes a severe challenge in the prediction of in situ biogeochemical transformation rates and further of nutrient loading contributed by the groundwater to the surface water bodies. Therefore, we used a numerical modelling approach to evaluate the sensitivity of groundwater microbial biomass distribution and nutrient cycling to spatial heterogeneity in different scenarios accounting for various residence times. The model results gave us an insight into domain characteristics with respect to the presence of oxic niches in predominantly anoxic zones and vice versa depending on the extent of spatial heterogeneity and the flow regime. The obtained results show that microbial abundance, distribution, and activity are sensitive to the applied flow regime and that the mobile (i.e. observable by groundwater sampling) fraction of microbial biomass is a varying, yet only a small, fraction of the total biomass in a domain. Furthermore, spatial heterogeneity resulted in anaerobic niches in the domain and shifts in microbial biomass between active and inactive states. The lack of consideration of spatial heterogeneity, thus, can result in inaccurate estimation of microbial activity. In most cases this leads to an overestimation of nutrient removal (up to twice the actual amount)
\end{abstract}

along a flow path. We conclude that the governing factors for evaluating this are the residence time of solutes and the Damköhler number $(D a)$ of the biogeochemical reactions in the domain. We propose a relationship to scale the impact of spatial heterogeneity on nutrient removal governed by the $\log _{10} D a$. This relationship may be applied in upscaled descriptions of microbially mediated nutrient cycling dynamics in the subsurface thereby resulting in more accurate predictions of, for example, carbon and nitrogen cycling in groundwater over long periods at the catchment scale.

\section{Introduction}

The Earth's critical zone comprises the near surface, surface, and sub-surface compartments, from the top of the vegetation canopy to aquifers in the bedrock (Giardino and Houser, 2015; Küsel et al., 2016). Biogeochemical processes impact most ecosystem functions (and consequently ecosystem services) in the critical zone by controlling the distribution of nutrients in the compartments of the critical zone. All these compartments are connected by water fluxes. Within the critical zone, the soil and deeper subsurface compartments account for almost $50 \%$ of the global carbon budget, and the subsurface is also one of the biggest storage compartments of nitrogen (McMahon and Parnell, 2014; Schlesinger and Andrews, 2000). 
Especially the subsurface part of the critical zone exhibits high spatial and temporal variability in environmental conditions that have been proven to be correlated with subsurface nutrient dynamics (Cole et al., 2007; Harden et al., 1997; Holt, 2000; Küsel et al., 2016; van Leeuwen, 2000). Since studies investigating these links are limited to nearsurface soil zones, e.g. focusing on the root zone (Küsel et al., 2016), studies linking surficial events with nutrient dynamics in the deeper subsurface are limited. Some research however shows that both subsurface heterogeneity and input variation affect subsurface microbial community structure. Schwab et al. (2017), Zhou et al. (2012), and Hofmann et al. (2020) linked changing diversity of microbial communities in groundwater with spatio-temporal variation in the groundwater physico-chemical quality. McGuire et al. (2000) and Benk et al. (2019) linked changing composition of terminal electron acceptors and of dissolved organic matter (DOM) in groundwater with surficial events, respectively. Their results also indicated further links with microbial community evolution, but they were unable to resolve the effect of transport in the subsurface presumably due to unresolved spatial heterogeneity. All the aforementioned studies combined establish a link between spatio-temporal variability in environmental conditions and nutrient cycling. However, this link is not yet quantitatively characterized. Therefore, this further impedes the predictability of biogeochemical cycles.

Improved prediction of biogeochemical cycles requires advancement in the mechanistic understanding of governing factors. Microbial communities play a key role in these biogeochemical cycles since they mediate nearly all the naturally occurring processes that contribute to these cycles. Recent advances in microbial techniques have led to greater insight into the functions of microbial communities for biogeochemical transformations in laboratory-scale batch and column experiments (Ballarini et al., 2014; Grösbacher et al., 2018). However, transferring this knowledge to the subsurface is challenging. For instance, the growth conditions used in laboratory studies are favourable with high substrate concentrations and readily accessible terminal electron acceptors (Grösbacher et al., 2018; Hofmann and Griebler, 2018). This is not representative of the subsurface as the subsurface is a spatially heterogeneous medium. Spatial heterogeneity influences subsurface microbial and nutrient dynamics by limiting access to nutrients and electron acceptors (Murphy et al., 1997), thereby influencing the distribution of active, inactive, suspended, and attached microbes as well (Grösbacher et al., 2018; Couradeau et al., 2019). Inactive microbes were found to account for $60 \%$ to $80 \%$ of total microbial biomass in soil (Lennon and Jones, 2011), and attached microbes commonly form the majority of microbial biomass fraction in the subsurface (Griebler and Lueders, 2009; Grösbacher et al., 2018). However, data on these fractions for groundwater systems are still scarce. Investigating the impact of spatially heterogeneous media on microbial biomass and nutrient cycling in the subsurface is hindered by the limited observa- tional opportunities, lack of visualization of real-time conditions, and limitations of sampling methods and oligotrophic conditions (growth limiting) in groundwater (Ballarini et al., 2014; Hofmann and Griebler, 2018). Since the critical zone is a complex system with non-linear process dynamics, governing factors are difficult to isolate, and their impact is unfeasible to quantify (Grösbacher et al., 2018). To overcome these limitations, numerical modelling approaches are powerful alternatives to undertake such investigations (Molins et al., 2014).

Formulating a conceptual model for microbially mediated carbon and nitrogen dynamics in the subsurface requires a two-pronged approach. First, the reaction network should be representative of a system's chemical and biological species, and second, the flow component of the model should be representative of a system's flow and transport pathways. Biogeochemical reaction networks have been explored extensively over the past decades with improvement in the conceptual understanding of the transient environmental conditions of the critical zone, the microbial life cycle, and the key processes involved in carbon and nitrogen cycles (Thullner and Regnier, 2019; Manzoni and Porporato, 2009). Incorporating microbially explicit reaction networks in reactive transport models is beneficial as these models could capture transient conditions and associated impacts (Thullner et al., 2007). In contrast to soil-based models that account for complex reaction networks, often comprising more than one microbial functional group (Yabusaki et al., 2017b; Thullner et al., 2007; Thullner and Regnier, 2019; Manzoni and Porporato, 2009), the reaction networks used for modelling biogeochemical processes in deep sub-surface domains are seldom complex. They do not account for microbially explicit models and relevant microbial life processes or any interactions thereof (Thullner and Regnier, 2019). A straightforward application of the soil-based biogeochemical model approaches to conditions in deeper subsurface compartments is problematic because the nature of carbon source changes as it travels into the deeper zones. A reaction network that is sufficiently representative of growth conditions found in the subsurface is lacking and must be conceptualized to study both microbial dynamics and resulting nutrient dynamics. Below we present a possible reaction network for such groundwater settings.

The second challenge, as stated above, is to characterize the flow and transport in a heterogeneous medium. Several attempts have already been made to model microbially driven reactions in the subsurface (Yabusaki et al., 2017b; Thullner et al., 2005; Schäfer et al., 1998a; Hunter et al., 1998; Arora et al., 2016) at a regional scale with further investigations on the impact of temporal variation on microbial activity and microbially driven redox dynamics in riparian zones (Yabusaki et al., 2017a; Dwivedi et al., 2018; Arora et al., 2016). Conducting studies at this scale is relevant, but it lacks the spatial resolution of microbially mediated nutrient dynamics in the subsurface. Additionally, it is difficult 
to transfer the results to other geological settings (Tufenkji, 2007).

To understand the fundamental mechanisms (without the volume-averaging effect of large-scale studies) influencing microbial activity, several studies worked on identifying factors influencing microbial activity at the pore scale (Stolpovsky et al., 2011; Meile and Tuncay, 2006; Heße et al., 2010; King et al., 2010; Gharasoo et al., 2012). Exploring microbial dynamics at the pore scale requires the knowledge of pore-scale features and/or geometry for practical applications (Heße et al., 2010), which is typically not available. Additionally, utilizing the pore-scale resolution as the base for modelling catchment-scale nutrient cycles is computationally problematic. Meanwhile, field groundwater sampling techniques reflect average conditions at the continuum scale depending on the sampling resolution. Sanz-Prat et al. (2016) attempted to simplify reactive transport modelling in heterogeneous media at the metre scale by proposing a travel time approach but considered a limited reaction network comprising only growth and decay dynamics of aerobic degraders and denitrifiers. The study conducted by Jung and Meile (2019) applied first-order reactions in heterogeneous porous media at the Darcy scale (or continuum scale) and further upscaled the effective reactions to the regional scale. Microbial kinetics and interplay between different functional groups thereof are more accurately expressed using Monodderived kinetics (Arora et al., 2016; Thullner et al., 2007), although Liu et al. (2019) attempted to identify the conditions in which first-order rates may be suitably used in soil systems to optimize computational efforts at field or regional scales. In summary, model attempts have been related to the regional and pore scale, leaving a gap at the soil core, rock core, and groundwater sampling scale.

In this research, we aim to study nutrient dynamics using a comprehensive reaction network at the continuum scale (sub-metre scale in our case). This provides the link between the pore-scale microbial dynamics and regional-scale microbial dynamics. It assists in developing a process-based understanding of the impact of spatial heterogeneity on microbial activity and subsequent nutrient dynamics and assists in scaling the activity to pragmatic regional scales accounting for spatial heterogeneity.

We seek to describe the influence of spatial variability in terrestrial subsurface settings (i.e. porous aquifer properties) on the in situ biogeochemical function of microorganisms through numerical simulations. Since preferential flow paths have been established to control access to nutrients and electron acceptors and thus influence the emergence of microbial hotspots (Franklin et al., 2019), we focus on investigating spatial heterogeneity alone. We use a complex reaction network that considers varying microbial functional groups (both aerobes and anaerobes) and key microbial life processes in a variety of redox conditions (aerobic, ammonia oxidizing, nitrate reducing and sulfate reducing) that eventually influence carbon and nitrogen transformation. Simulated scenarios are informed by data from the literature and from a subject site to describe realistic although generic conditions, which allows us to combine these conditions with different types of subsurface heterogeneities to determine the resulting biogeochemical potential of the subsurface system. The results of this study support the identification of key drivers of microbial dynamics in the critical zone and assist in effective upscaling of these process descriptions. This, in turn, contributes towards the regional-scale modelling of biogeochemical cycles resulting from microbial dynamics.

\section{Methods}

This study investigates the impact of spatial heterogeneity of the aquifer matrix on nutrient cycling in groundwater with a focus on carbon and nitrogen using reactive transport modelling. For this we used a numerical reactive transport modelling approach which considered the microbial abundance and activity in spatially heterogeneous environmental conditions, that is, spatial variations in aquifer permeability. We used the geochemical and geomicrobial observations from our subject site in the Hainich Critical Zone Exploratory (CZE; Küsel et al., 2016) as the foundation of the conceptual model to investigate the research questions. The subject site was set up under the DFG (German Research Foundation) Collaborative Research Centre grant 1076 AquaDiva to study the links between surficial processes and subsurface dynamics. Thus, it provides spatially and temporally resolved field observations to enable the formulation of a representative conceptual model. We used this information to constrain our conceptual approach and the simulated scenarios to realistic conditions. It is, however, not the aim to explicitly simulate a specific part of the subject site. For some model input we rather considered values at the extreme end of possible conditions to enlarge the range of conditions covered by our model scenarios. We ran all simulations for a two-dimensional transect of $50 \times 30 \mathrm{~cm}$ size assuming fully saturated conditions, steady-state flow, and constant inflow concentrations of dissolved species. We deemed this domain size appropriate to investigate sub-sampling-scale (submetre-scale) heterogeneities. We considered three different average flow velocities and 12 scenarios of hydraulic conductivity fields of varying heterogeneity for all simulations. The following sections describe the conceptual model comprising reaction network, flow regime and corresponding parameterization, the simulated scenarios, and methodology of analyses of the simulation results.

\subsection{Reaction network}

We conceptualized an extended biogeochemical process network to describe the turnover of carbon and nitrogen (Appendix A and Fig. 1). The reaction network is an extended adaptation of the carbon dynamics described by Vogel et 
al. (2018), as well as relevant processes in the subsurface as implemented by Manzoni and Porporato (2009). The network accounts for autotrophy and heterotrophy in both aerobic and anaerobic regimes considering four functional groups of microorganisms: aerobic dissolved organic carbon (DOC) degraders, nitrate reducing DOC degraders, ammonium oxidizers, and sulfate reducing DOC degraders.

The network accounts for other observed microbial processes such as dormancy and mortality using a modified dual-Monod approach adapted from Stolpovsky et al. (2011). The reaction network also accounts for the "maximum carrying capacity" of the matrix (Ding, 2009; Grösbacher et al., 2018), lumping all growth-limiting effects not explicitly accounted for into an additional term (Prommer et al., 1999; Schäfer et al., 1998b; Thullner et al., 2007; Wirtz, 2003). Eventually the carbon and nitrogen loop are completed via recycling of bacterial necromass. Furthermore, the reaction network accounts for microbial attachment, in the case of hospitable conditions, and detachment, which is due to inhospitable conditions or velocity of the water (see Sect. A.3.3). The detached mobile bacteria are transported by the flowing water.

\subsection{Flow and transport}

We modelled steady-state flow conditions in each fully saturated domain $(50 \times 30 \mathrm{~cm}$ in size $)$ by imposing fixed hydraulic heads at the inlet and outlet of the domain, adjusting the inlet value to achieve the desired average flow velocity. We kept the head at both inlet and outlet constant throughout the simulation periods ensuring steady-state flow conditions. All simulated domains had a constant porosity of 0.2 and an average hydraulic conductivity of $2.0 \times 10^{-6} \mathrm{~m} \mathrm{~s}^{-1}$. The transport regimes account for advection, dispersion, and diffusion. We assumed inlet concentrations of mobile species to be constant for all simulations.

\subsection{Parameterization}

The subject site is a monitoring well transect within the Hainich CZE in the Hainich National Park, Thuringia, Germany. Groundwater characteristics and composition of microbial communities observed in the groundwater of the subject site over 5 years (Küsel et al., 2016) informed the parameterization of the model.

As model input, we introduced a solution which was representative of water infiltrating from the shallow subsurface (Table A3), containing a mixture of naturally derived dissolved organic carbon (DOC), dissolved oxygen (DO), nitrate, sulfate, and some mobile microorganisms (heterotrophic aerobic degraders, heterotrophic nitrate and sulfate reducers, and autotrophic ammonia oxidizers) in the domain. The concentrations of the reactive species mimicked conditions observed in the subject site.

\subsection{Simulated scenarios}

We performed simulations for three different flow regimes, each characterized by a specific average flow velocity: for the slow flow regime, the average flow velocity of $3.8 \times$ $10^{-4} \mathrm{~m} \mathrm{~d}^{-1}$ is given by the estimated recharge rate at the subject site (Kohlhepp et al., 2017; Jing et al., 2018) and represents the slow migration of water through the uppermost part of the saturated aquifer. We increased the average flow velocity by a factor of 10 for the medium flow regime and by a factor of 100 for the fast flow regime (Table 1).

For each flow regime, a base case scenario accounted for a homogeneous flow field; i.e. the homogeneous domains did not have any variation in the distribution of conductivity field and no associated anisotropy. Further scenarios considered spatial heterogeneity of the flow field using randomly generated hydraulic conductivity fields (Heße et al., 2014). Each random field was characterized by the same mean value of conductivity (i.e. average conditions at the subject site; Jing et al., 2018) and spatial autocorrelation length scale $(0.1 \mathrm{~m})$ in all realizations, scaling with the size of the domain in line with previous studies (Turcke and Kuper, 1996; Welhan and Reed, 1997; Desbarats and Bachu, 1994). To conceptualize heterogeneity, we used a limited parameter set (i.e., variance in the log normal distribution of conductivity and anisotropy) to represent varying porous and fractured media and to also control the degree of channelized flow in the domain (Edery et al., 2016; Heße et al., 2014). We varied the values of these parameters within ranges reflecting the site conditions and geological features at the study site (Heath, 1983; Kohlhepp et al., 2017). The scenarios are summarized in Table 2. In total, we ran 147 simulations for the three different flow regimes in spatially heterogeneous domains. We kept the average water fluxes the same in all scenarios, and we compared the results of the scenarios with the base case scenario. We used the breakthrough of a constantly injected conservative tracer as a measure of the solute residence time (i.e. time for flux-averaged outlet concentration to reach $50 \%$ of inlet value) in the system.

\subsection{Numerical tools}

We used OGS-BRNS (Centler et al., 2010) to carry out the numerical simulations. This numerical model couples the BRNS (Biochemical Reaction Network Solver; Aguilera et al., 2005; Regnier et al., 2002), an established tool that allows for the simulation of reaction networks of arbitrary size and complexity (Thullner et al., 2005), with OGS (Open Geosys), a state-of-the-art open-source thermohydro-mechanical-chemical (THMC) simulator (Kolditz et al., 2012) that has also been used for modelling groundwater flow and transport (Jing et al., 2018). We used a constant finite volume discretization of $0.01 \mathrm{~m}$ in both directions. Transient simulations were performed until steady state was achieved. 


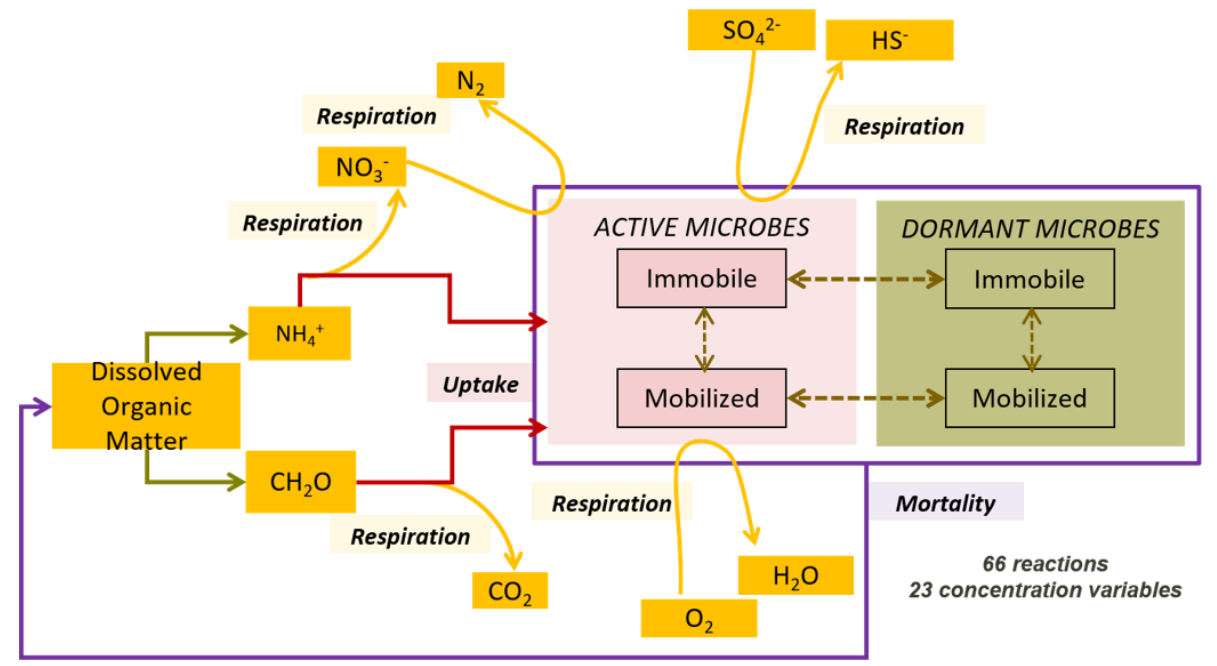

Figure 1. Schematic representation of the simulated biochemical reaction network.

Table 1. Flow and transport parameters considered in the simulations and the resulting Péclet number $(P e)$ associated with the different flow regimes. For the latter, the domain size of $0.5 \mathrm{~m}$ was used as a characteristic length for all flow regimes.

\begin{tabular}{lrrr}
\hline Property & Slow flow & Medium flow & Fast flow \\
\hline Darcy velocity $\left(\mathrm{m} \mathrm{d}^{-1}\right)$ & $3.8 \times 10^{-4}$ & $3.8 \times 10^{-3}$ & $3.8 \times 10^{-2}$ \\
Diffusion coefficient $\left(\mathrm{m}^{2} \mathrm{~d}^{-1}\right)$ & $8.64 \times 10^{-5}$ & $8.64 \times 10^{-5}$ & $8.64 \times 10^{-5}$ \\
Longitudinal dispersivity $(\mathrm{m})$ & 0.02 & 0.02 & 0.02 \\
$P e(-)$ & 2.02 & 11.7 & 22.45 \\
\hline
\end{tabular}

Table 2. Summary of spatially heterogeneous scenarios investigated for each flow regime. S. no. 1 is the homogeneous base case.

\begin{tabular}{lrrrr}
\hline $\begin{array}{l}\text { S. } \\
\text { no. }\end{array}$ & $\begin{array}{r}\text { Variance in } \\
\text { permeability }\end{array}$ & Anisotropy & $\begin{array}{r}\text { Number of } \\
\text { realizations }\end{array}$ & $\begin{array}{r}\text { Category } \\
\text { type }\end{array}$ \\
\hline 1 & 0 & $\mathrm{n} / \mathrm{a}$ & 1 & $\begin{array}{r}\text { Homogeneous (referred to } \\
\text { as } 0: 1 \text { in Fig. } 2)\end{array}$ \\
& & & & $0.1: 2$ \\
2 & 0.1 & 2 & 4 & $0.1: 5$ \\
3 & 0.1 & 5 & 4 & $0.1: 10$ \\
4 & 0.1 & 10 & 4 & $1: 2$ \\
5 & 1 & 2 & 4 & $1: 5$ \\
6 & 1 & 5 & 4 & $1: 10$ \\
7 & 1 & 10 & 4 & $5: 2$ \\
8 & 5 & 2 & 4 & $5: 5$ \\
9 & 5 & 5 & 4 & $5: 10$ \\
10 & 5 & 10 & 4 & $10: 2$ \\
11 & 10 & 2 & 4 & $10: 5$ \\
12 & 10 & 5 & 4 & $10: 10$ \\
13 & 10 & 10 & 4 & \\
\hline
\end{tabular}

We used the Python programming language (van Rossum and Drake, 2006) (referred to as Python henceforth) to set up the scenarios for running the simulations using OGS-BRNS. These tasks included the generation of input files. We used ogs5py (Müller, 2020) to generate the input files for running the simulations in OGS-BRNS. We used gstools (Müller and Schüler, 2019) to generate the spatial random fields to represent heterogeneous domains in OGS-BRNS. We processed and further analysed simulation results using a workflow in Python as well. We also used Python to generate all graphical outputs presented in this paper. The scripts used for the Python workflow along with the input files are available in a repository for ease of reproducibility (Khurana et al., 2021).

\subsection{Data analysis}

The Péclet number $(P e)$ indicates the relative importance of flow processes in the flow regime. The resulting $P e$ of each flow regime (calculated using Eq. 1) increased from 2 indicating a mixed diffusion-advection-transport regime for the slow flow regime to 22 indicating fully advection-dominated transport for the fast flow regime (see Table 1 for further details).

$P e=\frac{v_{\mathrm{eff}} \cdot l}{D+\alpha \cdot v_{\mathrm{eff}}}$,

with $v_{\text {eff }}$ as effective Darcy velocity, $l$ as length scale, $D$ as diffusion coefficient, and $\alpha$ as longitudinal dispersivity.

The breakthrough time is a useful metric to evaluate the matter flux in the domain. We defined the breakthrough time of a conservative tracer as the time taken for the fluxaveraged concentration at the outlet of the domain to be $50 \%$ of the continuous tracer input concentration at the inlet of the domain. This also enables the evaluation of the impact of 
spatial heterogeneity on matter flux alone without considering the impact of reactions.

To evaluate the impact of spatial heterogeneity on nutrient cycling, we calculated the removal of reactive species (that is, DOC, DO, ammonium, and nitrate) from the domain in steady-state conditions. Thus, while the chemical species entering the domain at the inlet were consumed at varying rates by the microbial species present in the system, the rate of consumption was constant in time in each domain in all flow regimes. In addition to these dissolved reactive species, we also considered (total) nitrogen and total organic carbon (TOC) concentrations by considering also nitrogen and carbon present in the mobile microbial biomass and in particulate organic matter being transported in the domain (Appendix A). We compared the changing mass removal in heterogeneous domains with the respective base case scenarios (homogeneous domains).

To evaluate the key factors determining the impact of spatial heterogeneity on nutrient cycling, we undertook a series of multivariate statistical analyses of the simulation results using linear mixed effect modelling, progressively including variables in both fixed effects and random effects. We compared the Akaike information criterion (AIC) of each model to evaluate the fit of the model. AIC is an indicator of prediction error associated with a general linear model. It is an indicator of relative performance of a group of models; the model with the lowest AIC is concluded to be the one with the least prediction error or the best performance. With each iteration of the model, we selected the features most influencing the performance of the model and reducing the AIC of the predictions. We described these key factors using established dimensionless numbers which are also identifiable by observations. For example, we used $P e$ to indicate different flow regimes (described in Sect. 2.4). Similarly, we used the Damköhler number $(D a)$ to indicate the reaction regime for each reactive species. $D a$ is defined as the ratio of the transport timescale and the reaction timescale as described in Eq. (2).

$D a=\frac{\tau_{\text {transport }}}{\tau_{\text {reaction }}}$,

where $\tau_{\text {reaction }}$ is the characteristic reaction timescale, and $\tau_{\text {transport }}$ is the characteristic transport timescale given by the breakthrough time of a conservative tracer in the domain. We adapted this definition to derive the characteristic reaction timescale assuming $63 \%$ loss (Pittroff et al., 2017) and used Eq. (3) below to calculate the apparent $D a$ using values estimable in the field when $\frac{C_{\text {out }}}{C_{\text {in }}}>5 \%$.

$D a=-\ln \frac{C_{\text {out }}}{C_{\text {in }}}$,

with $C_{\text {in }}$ as flux-averaged concentration of a reactive species entering the domain and $C_{\text {out }}$ as flux-averaged concentration of the reactive species leaving the domain. In the case of
$\frac{C_{\text {out }}}{C_{\text {in }}} \leq 5 \%$, we used Eqs. (4) and (5) to derive the apparent $\mathrm{Da}$ of the chemical species:

$$
\begin{aligned}
& \tau_{\text {reaction }}=\frac{-\ln (0.37)}{-\ln \left(\frac{C_{y 5}}{C_{\text {in }}}\right)} \times \tau_{y 5}, \\
& \tau_{\text {reaction }}=\frac{\tau_{y 5}}{\ln \left(\frac{C_{y 5}}{C_{\text {in }}}\right)},
\end{aligned}
$$

where $C_{y 5}$ is the concentration of the chemical species at the first cross-section $(y=y 5)$ when $\frac{C}{C_{\text {in }}} \leq 5 \%$, and $\tau_{y 5}$ is the breakthrough time for a conservative tracer at the same crosssection; i.e. $y=y 5$. $\tau_{\text {transport }}$ in this case was the same as the breakthrough time of the conservative tracer in the domain (Eq. 6).

$$
D a=\frac{\text { breakthrough time }}{\frac{\tau_{y 5}}{\ln \left(\frac{C_{y 5}}{C_{\text {in }}}\right)}}
$$

Thus, we were able to characterize reaction-dominant systems where $D a>1$. We took the logarithm of $D a$ to the base $10\left(\log _{10} D a\right)$ to characterize the regime for each reactive species in each domain.

For a scalable relationship addressing the impact of spatial heterogeneity on reactive species removal, we conduct a simple linear regression analysis of species removal vs. residence time (both in relative units to the homogeneous reference cases) for different $\log _{10} D a$ ranges.

For comparison we also use the following expression to predict the impact of reducing breakthrough time on the removal of reactive species in the case of a first-order removal rate expression (Eq. 7):

$C_{t}=C_{\mathrm{i}} e^{-k t}$,

with $C_{\mathrm{i}}$ as initial concentration of reactive species $\left[\mathrm{ML}^{-3}\right]$, $C_{t}$ as concentration of reactive species at time $t\left[\mathrm{ML}^{-3}\right], k$ as first-order rate constant $\left[T^{-1}\right]$, and $t$ as time taken for the reaction to occur $[T]$.

Then it follows that normalized removal of reactive species may be described with the following:

$\frac{C_{\mathrm{i}}-C_{t}}{C_{\mathrm{i}}}=1-e^{-k t}$.

To compare the removal of reactive species between two different time points, we use the following:

Impact on removal of reactive species with

respect to base case $=\frac{1-e^{-D a . t f}}{1-e^{-D a}}$,

with $t f$ as the ratio of the time taken for the reaction to take place in the two (2) different scenarios. In our study, this is the same as the ratio of breakthrough time in the heterogeneous domain and that in the base case. Furthermore, we 
calculated the impact of reducing breakthrough time on the removal of reactive species in the case of a zeroth order (i.e. constant) removal rate $R_{0}$ as

Impact on removal of reactive species with respect to base case $=t f R_{0}$.

\section{Results}

We compare characteristics of flow and transport of porous media such as conservative tracer breakthrough, microbial biomass in the domain, and nutrient removal from the domain for heterogeneous domains and the base case. The base case is the homogeneous domain in all the three considered flow regimes. We explore flux-averaged concentrations of mobile species and spatially averaged concentrations of immobile species in 1-D, along the predominant flow direction, and explore the two-dimensional concentration heat maps of the domain to compare the information lost when neglecting spatial heterogeneity at scales smaller than that of the sample. We further consider the total microbial biomass present in the domain and nutrient removal from the domain as aggregated results and compare these between the heterogeneous domains and respective base cases.

\subsection{Base case (homogeneous domain with uniform flow rate) results}

The breakthrough time varied in the base case of each flow regime depending on the flow velocity in the domain. It was $205 \mathrm{~d}$ in the slow flow regime, $24 \mathrm{~d}$ in the medium flow regime, and $2.4 \mathrm{~d}$ in the fast flow regime.

As mentioned in Sect. 2.3, we set the concentration of the dissolved species at the inlet to be the same across all flow regimes and heterogeneity scenarios, while it varied at the outlet for each scenario. In all flow regimes DOC concentrations decreased continuously along the domain length, yet they remained at relatively high values. In other words, an active microbial DOC degradation in the entire domain was not significantly limited by the abundance of DOC itself. In the slow flow and medium flow regimes, the dissolved oxygen (DO) dropped to concentrations less than $3 \mu \mathrm{M}$ (common detection limit of DO sensors; ISO, 2014) within the top half (upgradient) of the domain, indicating anoxic conditions in the downgradient parts of the domain (Fig. S1). Along the 1-D flow path in the domains aerobic degradation rates decreased more and more at low concentrations of DO (below approximately $20 \mu \mathrm{M}$ ), while ammonia oxidation persisted. With DO concentration lowering further, nitrate concentration reduced, which is attributable to the activity of nitrate reducers at $\mathrm{DO}<15 \mu \mathrm{M}$ (Fig. S1). As the concentration of DO reduced, so did the biomass of aerobic degraders, while ammonia oxidizer biomass increased. This resulted in preferential occurrence of ammonia oxidation and nitrate reducers, as well as nitrate reduction further downgradient in the domain (Fig. S2). No sulfate reduction took place in any of the flow regimes; the concentration of nitrate was still high ( $>63 \mu \mathrm{M}$ in all flow regimes) down to the outlet. In contrast to the slow and medium flow regimes, DO concentration at the outlet of the fast flow regime $(\sim 4 \mu \mathrm{M}$ in the base case) indicated that both oxic zones and aerobic activity prevailed further downgradient in the domain, and consequently the growth of nitrate reducers was suppressed till further downgradient in the domain. Overall, the concentration profiles along the flow direction of the base case in all flow regimes were thus in agreement with redox hierarchy, wherein aerobic degradation occurred preferentially upgradient in the domain promoted by a relatively high concentration of aerobic degraders.

The removal of reactive species, DOC $(59.2 \%)$, DO (99.6\%), ammonium $(19.8 \%)$, and nitrate $(74.7 \%)$, was the highest in the slow flow regime (Table 3 ). The removal of the reactive species was related to the average flow velocities since it related directly to the residence time in the domain and reaction-dominated regimes. Hence, the rate of removal of all these reactive species reduced in the medium flow and fast flow regimes. Also the removal of total nitrogen was the highest in the slow flow regime ( $57 \%$ ), while the removal of TOC was the lowest there $(32.6 \%)$ and highest in the medium flow regime $(42.6 \%)$.

The concentration of microbial species in different states of activity and locations in the domain is shown in Table 4. The total biomass concentration was the highest in the slow flow regime $(122 \mu \mathrm{MC})$, while it was the lowest in the fast flow regime $(86 \mu \mathrm{MC})$. This reduction was mainly attributed to a decrease in mobile biomass concentration with increasing flow rate, while the total concentration of immobile biomass remained constant with changing flow regimes. In all the flow regimes, the aerobic degraders formed the dominant species primarily due to the influx of oxygenated water at nearly saturation levels entering the domain at the inlet. In the slow flow regime, the highest proportion of biomass was contributed by inactive microbial species ( $>90 \%$ of the total biomass concentration). The proportion of active aerobic degraders and ammonia oxidizers was the lowest in the slow flow regime $(\sim 5 \%)$, while it increased in the medium flow regime $(\sim 17 \%)$ and was the dominating species in the fast flow regime $(\sim 87 \%)$. This was indicative of a small oxic zone with aerobic activity in the slow flow regime domain, which further expanded downgradient in the medium flow regime domain (Figs. S1 and S2). The dominance of the active aerobic degraders and increased presence of ammonia oxidizers in the fast flow regime domain indicated persistent oxic conditions and aerobic activity. Consequently, the proportion of active nitrate reducers was lowest in the fast flow regime $(\sim 3 \%)$, only growing in the downgradient direction near the outlet of the domain (Fig. S2). The medium flow regime provided the conditions for active nitrate reducers to sustain and form a substantial proportion of the microbial community ( $14 \%$ as opposed to $\sim 4 \%$ in the slow flow 
Table 3. Removal of dissolved species $\left(R_{\mathrm{b}}\right)$ in terms of mass flux $\left(\dot{m}\right.$ in $\mu$ mol $\left.\mathrm{d}^{-1}\right)$ from the homogeneous domain in three flow regimes slow flow, medium flow, and fast flow.

\begin{tabular}{lrrr|rrr|rrr}
\hline Dissolved species & \multicolumn{3}{c|}{ Slow flow } & \multicolumn{3}{c|}{ Medium flow } & \multicolumn{3}{c}{ Fast flow } \\
\hline & $\dot{m}_{\text {in }}$ & $\dot{m}_{\text {out }}$ & $R_{\mathrm{b}}(\%)$ & $\dot{m}_{\text {in }}$ & $\dot{m}_{\text {out }}$ & $R_{\mathrm{b}}(\%)$ & $\dot{m}_{\text {in }}$ & $\dot{m}_{\text {out }}$ & $R_{\mathrm{b}}(\%)$ \\
\hline DOC & 0.456 & 0.186 & 59.2 & 4.56 & 1.98 & 56.5 & 45.6 & 31.4 & 31.1 \\
DO & 0.143 & 0.001 & 99.6 & 1.43 & 0.01 & 99.4 & 14.3 & 0.2 & 98.4 \\
Ammonium & 0.0342 & 0.0274 & 19.8 & 0.342 & 0.276 & 19.4 & 3.42 & 3.03 & 11.5 \\
Nitrate & 0.143 & 0.036 & 74.7 & 1.43 & 0.49 & 65.8 & 14.3 & 14.1 & 1.12 \\
Nitrogen & 0.178 & 0.077 & 57.0 & 1.78 & 0.84 & 53.1 & 17.9 & 17.6 & 1.90 \\
TOC & 0.470 & 0.316 & 32.6 & 4.70 & 2.70 & 42.6 & 47.0 & 36.3 & 22.7 \\
\hline
\end{tabular}

regime and $\sim 3 \%$ in the fast flow regime). Among the active microbial species, the immobile fraction was higher than the mobile fraction in all flow regimes (more than 7 times in the slow flow regime, more than 4 times in the medium flow regime, and more than 2 times in the fast flow regime).

\subsection{Tracer breakthrough times}

For each flow regime, the tracer breakthrough time in heterogeneous domains varied from that in the base case. With the increase in variance of the hydraulic conductivity field and increase in anisotropy in the domain, the breakthrough time was shorter compared to the base case (Fig. 2). This was a result of preferential flow paths that were introduced by the heterogeneous hydraulic conductivity fields. The same "category" (combination of variance and anisotropy) of heterogeneity induced varying impacts depending on the flow regime, with higher average flow velocities leading to relatively stronger reductions in the breakthrough times. This difference in the impact of heterogeneity on tracer breakthrough times and thus the residence time of solutes in the domain was attributed to the different Péclet numbers $(P e)$ of the regimes (Table 1). Diffusion played a stronger role in the transport processes in the slow flow regime, promoting mixing effects and reducing the influence of the preferential flow paths in heterogeneous domains. This resulted in the lower deviation in breakthrough time from the base case in the slow flow regime. In contrast, in the medium flow regime and in particular in the fast flow regime transport was dominated by advection with little mixing between flow paths. The preferential flow paths in the heterogeneous domains therefore had a higher influence on the resulting tracer breakthrough times and thus on the residence time of dissolved species in these regimes.

\subsection{Distribution of dissolved reactive species in heterogeneous scenarios}

Scenarios with a heterogeneous hydraulic conductivity distribution exhibited a heterogeneous flow velocity distribution with pronounced preferential flow paths emerging with increasing variance and/or anisotropy of the conductivity dis-

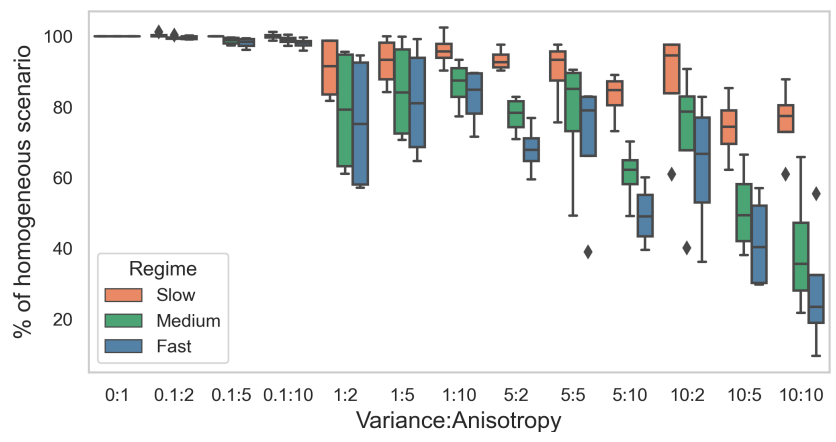

Figure 2. Breakthrough time in different heterogeneous scenarios (described as variance in permeability field:anisotropy) normalized by that in the base case (or homogeneous case) in three flow regimes: slow, medium, and fast flow.

tributions. The distribution of dissolved species in heterogeneous domains followed the orientation of the preferential flow paths (Fig. S3). All the species persisted longer along these preferential flow paths compared to the low permeability zones. Moreover, also on average all the reactive species penetrated further downgradient into the heterogeneous domains compared to the homogeneous domain due to the presence of the preferential flow paths (Fig. S1). For example, in the medium and fast flow regimes DO persisted further in the heterogeneous domain (deeper in the domain) as the groundwater flowed through preferential flow paths. This impact of heterogeneity on the longer persistence of DO was, however, not observable for the slow flow regime. This is because the DO was preferentially and quickly consumed by aerobic degraders close to the inlet of the domain in the slow flow regime, rendering more than $90 \%$ of the domain suboxic to anoxic with prevailing anaerobic activity. Effectively, spatial heterogeneity did not play a role in aerobic respiration in the slow flow regime. In contrast, a larger oxic zone with aerobic activity existed in the upgradient section of the domains in the medium and fast flow regimes. There, spatial heterogeneity resulted in observable shifts in the transition from the oxic to sub-oxic zone or from aerobic activity to anaerobic activity to further downgradient parts of the do- 
Table 4. Total biomass concentration ( $\mu \mathrm{MC}$ ) in homogeneous base case domains (volume averages) with fraction of biomass concentration (\%) of each microbial species for three flow regimes.

\begin{tabular}{lrrr}
\hline Microbial species & Slow flow & Medium flow & Fast flow \\
\hline Total & 122.0 & 93.34 & 86.35 \\
\hline Active fixed aerobes & 3.5 & 12 & 74 \\
Active fixed ammonia oxidizers & 0.5 & 2.5 & 2.4 \\
Active fixed nitrate reducers & 2.5 & 12 & 2.3 \\
Active mobile aerobes & 1.0 & 2.2 & 9.6 \\
Active mobile ammonia oxidizers & 0.2 & 0.7 & 0.7 \\
Active mobile nitrate reducers & 1.2 & 3.1 & 0.3 \\
Inactive fixed aerobes & 44 & 41 & 5.2 \\
Inactive fixed ammonia oxidizers & 0.5 & 0.2 & 0.2 \\
Inactive fixed nitrate reducers & 15 & 11 & 3.2 \\
Inactive mobile aerobes & 24 & 12 & 0.5 \\
Inactive mobile ammonia oxidizers & 0.3 & 0.1 & 0.3 \\
Inactive mobile nitrate reducers & 7.9 & 2.9 & 1.4 \\
\hline
\end{tabular}

main. Additionally, spatial heterogeneity resulted in oxic and anoxic mesh nodes co-existing along a cross-section that was apparently oxic (Fig. 3). Oxic mesh nodes were nodes where DO was recorded to be higher than $3 \mu \mathrm{M}$. We noted that even though the flux-averaged concentration decreased steadily in the downgradient direction, a high percentage of nodes along the cross-section remained oxic in heterogeneous domains. Because of this delayed transition, nitrate reduction was also affected. In heterogeneous domains, nitrate was observed to be respired further downgradient in the domain and at the interface of high flow and low flow zones (Fig. S3).

These concentration distributions translated into reduced removal of carbon and nitrogen in heterogeneous domains with increasing spatial heterogeneity compared to the base cases (Fig. 4). DOC removal was less than in the base case in all the flow regimes with the lowest removal reaching only $40 \%$ of the base case values in the fast flow regime. The removal of DO was reduced in the fast flow regime (down to $40 \%$ of the base case value), while no or negligible reductions were observed for most slow and medium flow scenarios. Nitrogen removal was reduced in the slow and medium flow regimes reaching at least $70 \%$ of base case values. One exception was nitrogen removal in the fast flow regime, which increased (up to 6 times the base values) compared to the base case. The dependency of TOC removal on spatial heterogeneity matched that of DOC for the different flow regimes (Fig. 4).

The above results could be summarized by the use of $\log _{10} D a$. The distribution of $\log _{10} D a$ is shown in Fig. S6. The same value of $\log _{10} D a$ is associated with different combinations of reaction and flow regimes. The aerobic reactions in the slow flow and the medium flow regimes were characterized with high values of $\log _{10} D a(>0.5)$, while the anaerobic reactions in the slow and medium flow regimes were characterized by mid-range values of $\log _{10} D a(0-0.5)$ along with the aerobic reactions in the fast flow regime. The anaerobic reactions in the medium flow regime were characterized by low values ( -1 to 0$)$ of $\log _{10} D a$. Lastly, the anaerobic reactions in the fast flow regime were characterized by extremely low values of $\log _{10} D a(<-1)$.

\subsection{Distribution of microbial biomass in heterogeneous scenarios}

As already shown in Sect. 3.1, the active immobile fraction of the biomass has a larger presence in the domain compared to the mobile fraction, thereby making a larger contribution to nutrient cycling. The median value of the mobile biomass in the domain varied from $98 \mu \mathrm{MC}$ (in the fast flow regime) to $320 \mu \mathrm{MC}$ (in the slow flow regime), out of which active mobile biomass varied from $8 \mu \mathrm{MC}$ (in the medium flow regime) to $15 \mu \mathrm{MC}$ (in the fast flow regime). Immobile biomass in comparison was in the order of $300 \mu \mathrm{M}$ in all flow regimes, out of which active immobile biomass varied from $29 \mu \mathrm{M}$ (in the slow flow regime) to $232 \mu \mathrm{M}$ (in the fast flow regime). Therefore, next we focus on the impact of spatial heterogeneity on the distribution of this important fraction of the biomass. Aerobic immobile degraders were found to be active and most abundant near the inlet of the domain, as well as along the preferential flow paths in the downgradient zone of the domain (Fig. S4). Ammonia oxidizers were active at the interfaces between high flow and low flow regions of the upstream parts of the system, co-existing with a high concentration of active aerobic degraders. Ammonia oxidizers were also active further downgradient in the system along the preferential flow paths. This may be due to the presence of DO at reduced concentrations in the downgradient region of the domain. DO at these concentrations and low DO/ammonium ratios can be preferentially taken up by ammonia oxidizers compared to aerobic degraders (Gu et al., 2006). The maximum concentration of active immobile ammonium oxidiz- 

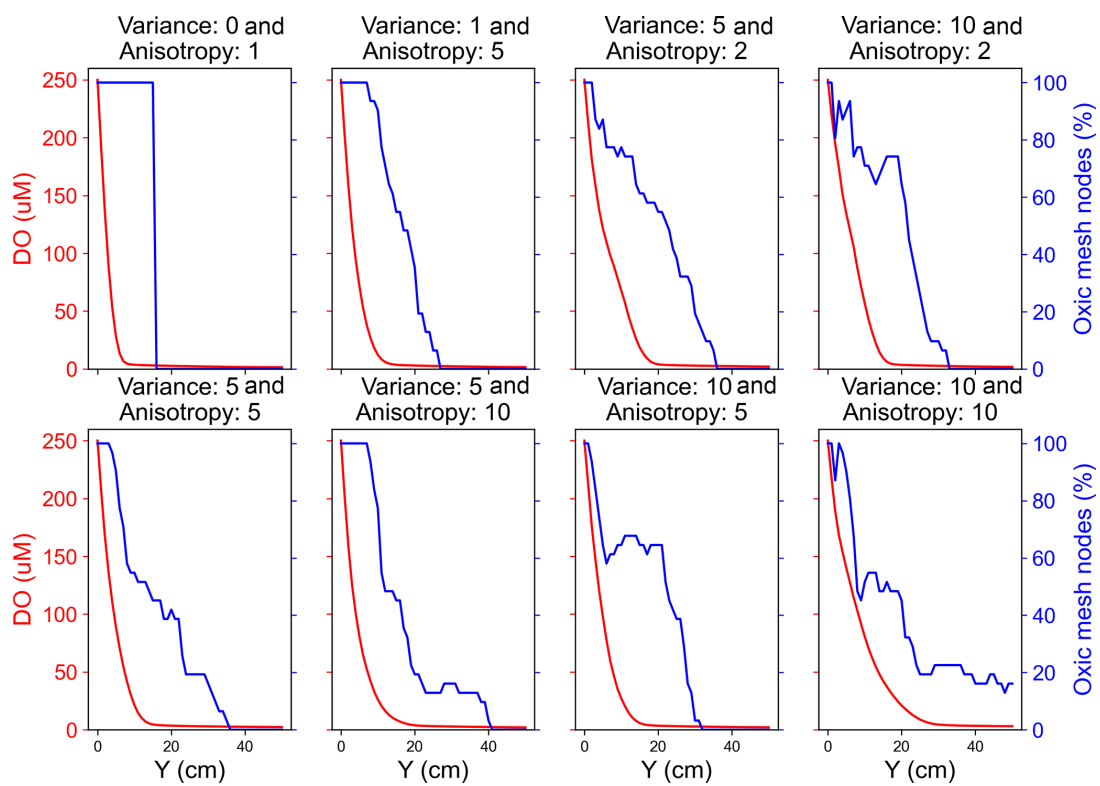

Figure 3. Comparison of flux-averaged DO concentration and percent of oxic mesh nodes (i.e. cells with DO concentration $>3 \mu \mathrm{M}$ ) along the flow direction in a medium flow regime.

ers was more than an order of magnitude lower than that of the active immobile aerobic degraders. Nitrate reducers were present in lower permeability zones in the heterogeneous domains, but close to the preferential flow paths, in response to the continuous supply of nutrients from the groundwater flowing through the domain. They co-existed with ammonia oxidizers but at higher concentrations. Active immobile nitrate reducers were much higher than active mobile nitrate reducers in the fast and medium flow regimes but comparable in magnitude in the slow flow regime.

The corresponding 1-D distribution of microbial species in heterogeneous domains was observed to vary from the base case given the same average water flux (Fig. S2). All the microbial species were prevalent along a larger section in the heterogeneous domains. Aerobic and anaerobic microorganisms also appear to co-exist in heterogeneous domains (solid lines) in contrast to their sequential occurrence in the base case (dashed lines).

The changing distribution pattern of the microbial species impacts the total active immobile biomass concentration in the domain, which diverges from the base case as heterogeneity increases (Fig. 5). The biomass of active immobile aerobic degraders decreased with increasing heterogeneity regardless of the flow regime, with the lowest values reaching only $40 \%$ of the base case biomass. The biomass of immobile active ammonia oxidizers and nitrate reducers also decreased with increasing heterogeneity in the slow $(\sim 75 \%$ and $\sim 90 \%$ of base case, respectively) and medium flow regimes (30\% and $85 \%$, respectively). However, the impact on the biomass of immobile active nitrate reducers was the reverse in the fast flow regime (increase to 5 times the con- centration in the base case). Lastly, there was no impact of spatial heterogeneity in the biomass of immobile active ammonia oxidizers in the fast flow regime.

Overall, active immobile biomass decreased with the increase in spatial heterogeneity in all the flow regimes, while active mobile biomass increased marginally (Fig. S9). Inactive immobile biomass reduced with spatial heterogeneity in the slow and medium flow regimes, while it increased in the fast flow regime. Lastly, inactive mobile biomass increased with heterogeneity in all flow regimes.

\subsection{Predicting impact of spatial heterogeneity on redox regimes.}

While conducting the multivariate statistical analysis of change in mass removal of reactive species, we made use of AIC to evaluate governing factors influencing mass removal in a spatially heterogeneous domain. The analysis indicated that AIC was 994 when considering only breakthrough time and chemical species. AIC reduced to -211 when the chemical species, the flow regime, variance in permeability field, and the anisotropy of the domain were included as random factors. Please refer to Table S1 for further details. Thus, we concluded that nutrient dynamics are influenced by spatial heterogeneity. Categorizing the systems using $\log _{10} D a$, we proposed a linear expression to predict the impact of spatial heterogeneity on nutrient removal. The regression parameters informing this expression are given in Table 5. The results indicated that we may underestimate nutrient removal by 6 times or overestimate it by twice the amount (Fig. 6). 


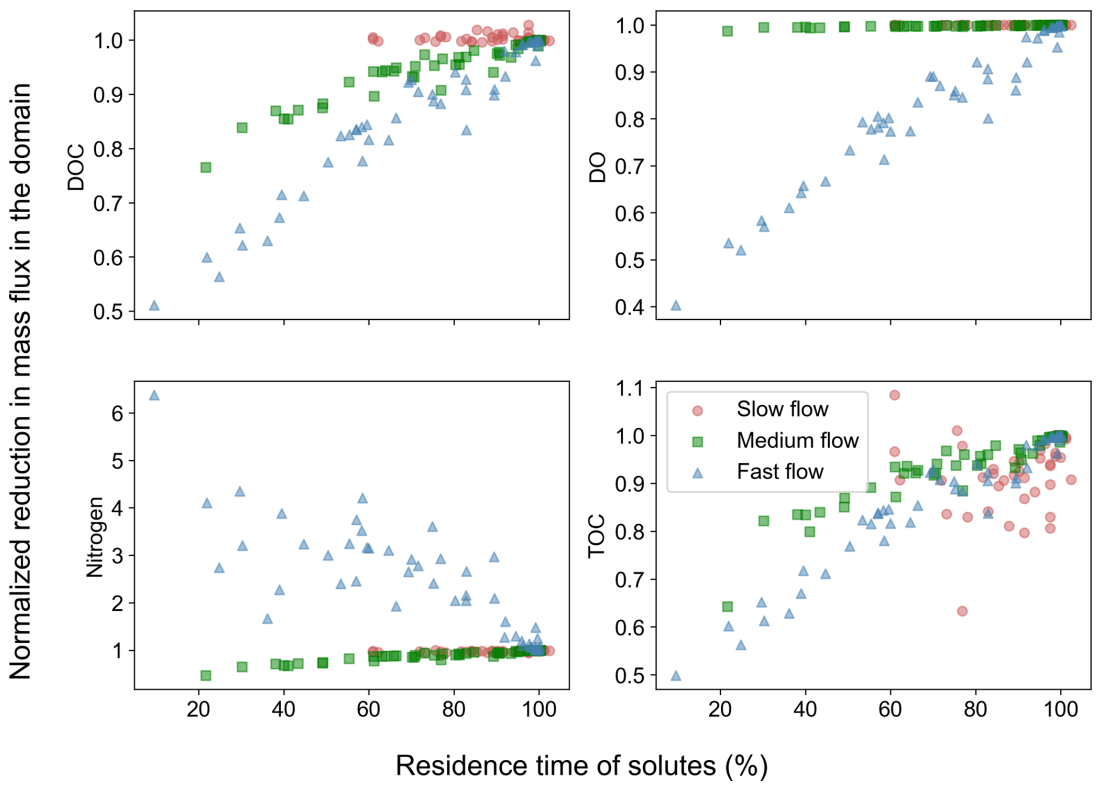

Figure 4. Removal of chemical species in spatially heterogeneous domains in different flow regimes. Values show mass flux differences between inlet and outlet of the heterogeneous domains normalized by the flux differences for the homogeneous base case of each flow regime.
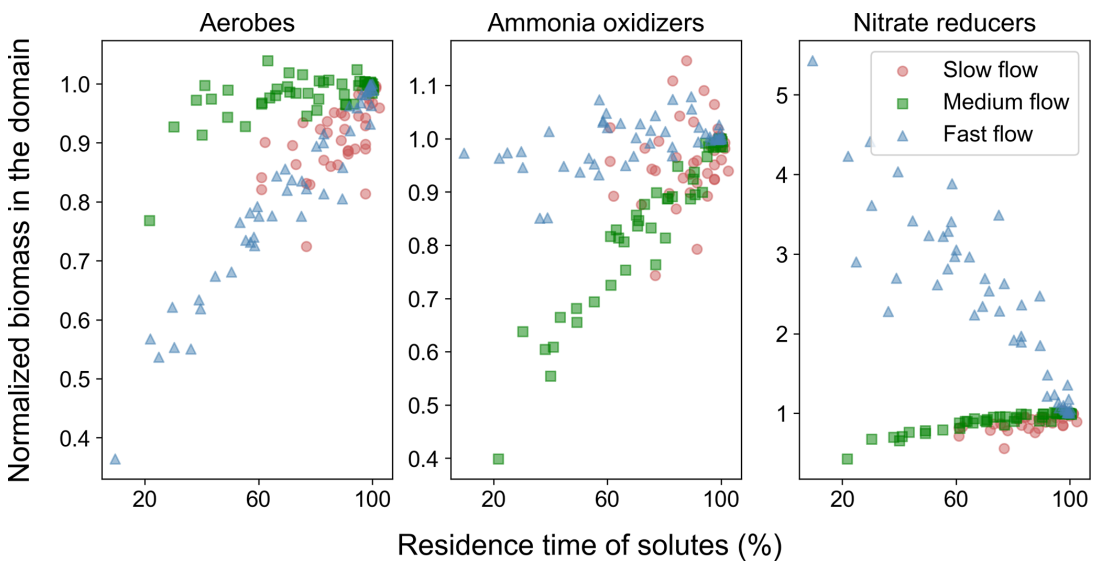

Figure 5. Biomass concentration of active immobile fraction of different species in spatially heterogeneous domains in different flow regimes. Shown volume-averaged values for the heterogeneous domains were normalized by values of the homogeneous base case of each flow regime.

Table 5. Regression parameters for predicting removal of chemical reactive species based on the reaction regime indicated by $\log _{10} \mathrm{Da}$.

\begin{tabular}{lrrr}
\hline Category of flow and & \multicolumn{3}{c}{ Regression parameters } \\
\cline { 2 - 4 } reaction regime & Slope & Intercept & RMSE \\
\hline $\log _{10} D a<-1$ & -365.0 & 497.3 & 57 \\
$-1<\log _{10} D a<0$ & 53.94 & 46.68 & 3.7 \\
$0<\log _{10} D a<0.5$ & 12.16 & 87.71 & 4.7 \\
$\log _{10} D a>0.5$ & 0 & 100 & - \\
\hline
\end{tabular}

\section{Discussion}

In this study we synthesized available process knowledge and observations from our subject site on geomicrobial activity in the deep subsurface, both terrestrial and marine, into a set of in silico scenarios on the fate of biogeochemically reactive compounds in heterogeneous subsurface settings. This approach allowed us to generate a wide range of spatially heterogeneous domains (with variance of the log normal distribution of conductivity varying from 0.1 to 10 , and anisotropy varying from 2 to 10 ), which is not possible experimentally. Therefore, we utilized geostatistical methods using variance in conductivity field and anisotropy to simulate heteroge- 
neous subsurface scenarios. Variance reflects naturally occurring variation in the conductivity field. In the case of a high variance, it represents scenarios in which lenses of a different medium are present in another medium (such as clay lenses in a sandy aquifer). Anisotropy provides an additional control to enforce channelized flow fields in the domain or layering processes in general, common in both alluvial sediments and fractured bedrock. Thus, we considered 12 scenarios for representing these heterogeneous flow fields, covering most physically (variance) and geometrically (anisotropy) plausible scenarios. At the same time, linking the extent of spatial heterogeneity with breakthrough time allowed us to discuss the impact of spatial heterogeneity on the removal of chemical species independently of how we generated the spatial heterogeneity.

The reaction network was formulated using literature knowledge and geomicrobial activity identified at the subject site. At the same time, it captures varying microbial respiration and growth regimes, from aerobic autotrophy to aerobic heterotrophy and anaerobic heterotrophy. The activity of geomicrobial reactive systems is dependent on a variety of factors, such as nutrient availability, access to energy gradients, $\mathrm{pH}$, pore size, hydraulic conductivity, and particle size distribution (Smith et al., 2018). The limited information on microbial activity applicable to oligotrophic conditions in the subsurface does challenge the parameterization of the reaction network, which is a priori a potential major source of uncertainty for the obtained model results. Given this limitation, we calibrated the parameters of the reaction network to ensure that it covers a sufficiently large range of $D a$ values and that it does not violate the established redox hierarchy in any of the flow regimes considered (see Appendix A and the base case results). Additionally, we consistently used our parameter set in all scenarios and used results of the homogeneous base cases as internal reference to which we compared results of the individual heterogeneous scenarios as we aimed to study the impact of spatial heterogeneity on microbial activity and sub-surficial nutrient dynamics.

Lastly, the consideration of varying flow regimes in combination with the reaction network provides a view on both reaction-dominant systems and flow-dominant systems, indicated by the use of $D a$. This compensates for our approach wherein we do not explore additional scenarios varying concentrations of chemical species and their influence on microbial growth and distribution. By treating the analysis of results in terms of $D a$, we condense the discussion to effective rates of microbial activity given the presence of spatial heterogeneity of hydraulic conductivity. Thus, we are confident that the presented findings are not limited to the particular parameter set used in this study but that they are applicable widely.

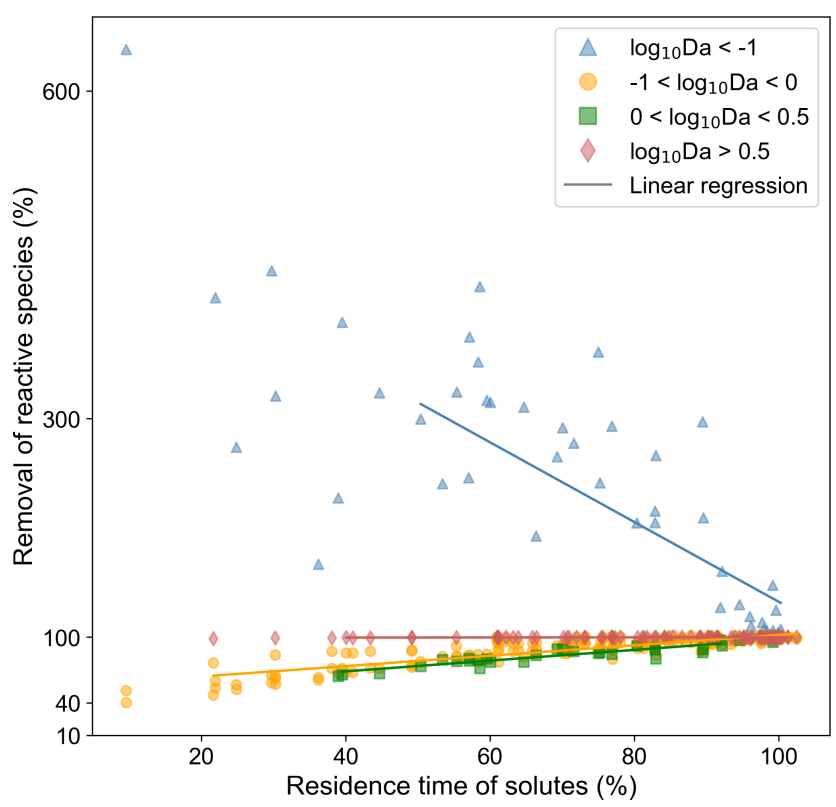

Figure 6. Regression analysis: predicting impact of spatial heterogeneity on chemical species removal in the different reaction regimes indicated by $\log _{10} D a$. Value on the $y$ axis indicate the removal of chemical species in heterogeneous domains normalized by that in the corresponding base case. Spatial heterogeneity is plotted on the $x$ axis, indicated by the breakthrough time in the heterogeneous domain normalized by that in the base case (homogeneous domain). A value of $100 \%$ on the $y$ axis indicates that the removal of the chemical species is the same as that in the corresponding base case (homogeneous domain). A value of $50 \%$ indicates that the removal of the chemical species was reduced by half in the corresponding heterogeneous domain. A value of 600 indicates that the removal of the chemical species in the heterogeneous domain was 6 times that in the homogeneous domain.

\subsection{Sampling and analysis: biomass and reactive species}

Microbial abundance can be derived from carbon content in the biomass using available conversion factors varying from 5-39 femtogram (fg) C per cell (Fukuda et al., 1998; Vrede et al., 2002). This resulted in median values of total mobile biomass in the domain of $10^{9}$ to $10^{11}$ cells L ${ }^{-1}$. Opitz et al. (2014) measured the total bacterial biomass in groundwater of the subject site to vary from $10^{6}$ to $10^{8}$ gene copies $\mathrm{L}^{-1}$ (depending on location, tapped aquifer, and season of measurement), which is lower than the simulated mobile values. However, the simulated values of mobile biomass are in the range derived in both lab-scale and field-scale studies (Holm et al., 1992; Griebler and Lueders, 2009; Grösbacher et al., 2018). Also, the mobile biomass concentration is in the range of particulate organic carbon concentration observed to be exported in the seepage at the subject site (Lehmann et al., 2021). The relatively high biomass values obtained in the simulations are attributed to the relatively high inflow con- 
centrations, as well as to the relatively high microbial reactivity we considered in the simulations to allow them to cover also high $D a$ ranges. We note that while the total biomass may not be matching the observations at the subject site, the relative composition of the microbial species fractions (that is, immobile, mobile, active, and inactive) follow established findings. For example, immobile microbial biomass indeed forms the majority biomass in the subsurface (as well as in our study), with its ratio with mobile biomass changing based on nutrient and other environmental conditions (Griebler et al., 2002; Grösbacher et al., 2018). It is proposed that the ratio of immobile and mobile biomass in Griebler et al. (2002) and Grösbacher et al. (2018) varies per nutrient availability, with higher ratios observed in oligotrophic conditions and lower ratios in nutrient rich conditions. We extend this further in our study by observing that the ratio depends on the Damköhler number, with higher ratios in low $D a$ systems and lower ratios in high $D a$ (reaction-dominant) systems. It is further estimated that $60 \%-80 \%$ of microbial biomass in soil may be inactive (Lennon and Jones, 2012). In our study, we observe these ranges in the slow flow and medium flow regimes but not in the fast flow regime. With newer technologies equipped to better characterize activity of microbes in environmental samples (Couradeau et al., 2019), we expect that it will be easier to draw the comparison in the future.

It is also important to note that the estimated abundance at the subject site varies with both sampling location and season. And as mentioned above, we also observe that microbial biomass may be in different states of activity (active or inactive) or location (immobile or mobile) depending on the flow regime and the structure of spatial heterogeneity in the system. This brings into focus that next to spatial heterogeneities addressed in this study also temporal variations in environmental conditions can have a significant impact on microbial abundance (Eckert et al., 2015). This study provides preliminary insights into how varying water velocities and flow regimes may impact the relative contribution of microbial species between inactive, active, mobile, and immobile fractions in spatially heterogeneous domains. The system may respond similarly to temporal fluctuations in groundwater velocities resulting from seasonal cycles as well. While this is not part of the current study, the presented conceptual approach and assessment scheme may be applied in future studies focussing on such transient effects.

Commonly used groundwater sampling techniques do not resolve the heterogeneous distribution of chemical and microbial species along the length and cross-section of a well screen, though specialized probes exist to characterize smallscale chemical variability in the subsurface (Ronen et al., 1987). The obtained samples may thus present a skewed or biased observation of the biogeochemical dynamics in the subsurface. For example, the gradual reduction of fluxaveraged DO concentration from near-saturation values at the inlet to below detection limit implies the continuous presence of an aerobic zone until DO is fully depleted. However, when the number of oxic and anoxic mesh nodes was calculated at each cross-section, it was evident that several oxic and anoxic regions can co-exist in an apparently oxic zone (Fig. 4). This results in unexpected observations wherein aerobes and anaerobes appear to be active in similar conditions, while in fact their zones of activity are spatially separated, and anaerobes are active in smaller zones that specifically provide hospitable conditions to their activity. Spatial heterogeneity allows for this apparent co-occurrence of several microbial species by providing appropriate niches. For instance, the biomass of immobile active nitrate reducers increased with spatial heterogeneity in the fast flow regime due to the introduction of sub-oxic pockets with anaerobic activity in low flow zones within a predominantly oxic zone with aerobic activity (Fig. S4). Seemingly overlapping conditions have also been observed by field-scale studies (Alewell et al., 2006; Waldron et al., 2009; Schwab et al., 2017; Lohmann et al., 2020), although the diversity of microbial communities varied in both space and time. Alewell et al. (2006), Schwab et al. (2017), and Lohmann et al. (2020) also noted that small-scale heterogeneities did not allow for the sequential redox hierarchy (as defined by energy yields of redox half reactions) to be applicable at the metre scale. We establish that the persistence of microbial species in the domain is governed by the presence of the appropriate carbon source and electron acceptor despite apparent co-existing microbial species that may be identified by groundwater sampling techniques that do not resolve sub-sampling-scale heterogeneities. Therefore, while mobility of microbial species using water as the medium may temporarily affect the composition of microbial communities, it is unlikely that mobile microbial species persist in high numbers at a location in the absence of sustained sources of nutrients and energy. This is further evident from the impact of spatial heterogeneity on microbial biomass distribution whereby active microbial biomass is only found to be persistent in high numbers in zones where reactive species are easily accessible. In addition, Kim et al. $(2009,2019)$ also suggested that groundwater redox chemistry and distribution of carbon pools are linked with geological controls such as hydraulic conductivity. The requirement of vertically discretized sampling has already been recognized (Ronen et al., 1987; Smith et al., 2018) and addressed by various sampling methodologies such as low flow sampling techniques, passive samplers, and point and discrete interval samplers (Ronen et al., 1987; Smith et al., 1991; Powell and Puls, 1993; Báez-Cazull et al., 2007; Anneser et al., 2008), even though heterogeneities at scales lower than that resolved by the sampling scheme will remain unobserved. Our results support the usefulness of such spatially resolved sampling techniques for the analysis of microbial activity in the groundwater. On the other hand, composite sampling from macro-scale matrix samples is useful to estimate the microbial activity in the sampled matrix core. This enables a more accurate estimate of microbial activity aggregated over the matrix core. 
The impact of heterogeneity on microbial biomass distribution has strong implications for evaluating sampling techniques and data obtained from groundwater samples. Immobile microbes account for more microbial activity compared to mobile microbes. However, groundwater samples represent mobile microbial biomass, termed as planktonic biomass (Smith et al., 2018). Estimates of microbial respiration are thereafter made based on the abundance of mobile microbes in the obtained groundwater samples. The results of this study suggest that the immobile microbes are, in fact, the major contributors to microbial respiration in the subsurface, which was also experimentally established by Alfreider et al. (1997), Griebler et al. (2002), and Grösbacher et al. (2018) by providing the link between heterogeneous structures in the domain, corresponding nutrient availability, and microbial biomass growth. Our results suggest that the relative composition of species in the mobile and immobile subcommunities is however similar (in part due to the same detachment and attachment properties assigned to the microbial species in this study) such that the assessment of microbial diversity based on the mobile fraction only would still be representative. However, this is not necessarily the case for nutrient cycling (see below).

Since spatial heterogeneity impacts microbial biomass distribution and microbial activity, it is not surprising that spatial heterogeneity also impacts carbon and nitrogen removal. Sanz-Prat et al. $(2015,2016)$ already established that travel time models are valid for use as reactive transport models in steady-state advective-transport conditions with other studies already discussing the same in surface waters and hyporheic zones (Liao and Cirpka, 2011; Painter, 2018). Painter (2018) also considers the application of travel time distribution as a representation of heterogeneity to be specific to the processes or reactive species being considered. We further this understanding by exploring a wider range of flow regimes, from locally mixed regimes to dominantly advective flow regimes and a complex process network exploring a variety of reactive species across both aerobic and anaerobic microbial processes. The impact on the removal of carbon resulting from heterogeneity is consistent for all flow regimes, with carbon removal decreasing in heterogeneous domains. For nitrogen removal the same trend is observed for the slow and medium flow regimes. In contrast, nitrogen removal in the fast flow regime increases with spatial heterogeneity as spatially heterogeneous domains provide the opportunity for anaerobic activity sub-zones to be sustained in predominantly oxic systems with aerobic regimes. As for the fast flow regime oxic conditions prevailed until the vicinity of the outlet of the simulated domain, nitrogen removal is mainly restricted to such sub-oxic sub-zones, and heterogeneity leads to an increased number of such sub-zones. It must be noted though that the concentration of nitrate decreases when and where the concentration of DO is below $15 \mu \mathrm{M}$ (Fig. S1) (De Brabandere et al., 2014; Kalvelage et al., 2013; Seitzinger et al., 2006). The reduced concentration of nitrate is attributable to the activity of nitrate reducers. It is assumed that for sufficiently long domains with sub-oxic conditions dominating the downstream parts, nitrogen removal would also exhibit a decreasing trend with heterogeneity, even for the fast flow regime. Therefore, travel time information is useful for estimating both carbon and nitrogen removal and identifying dominant microbial redox processes despite sub-scale heterogeneities allowing for the co-existence of several microbial species. Since immobile active microbial biomass was the major contributor to carbon and nitrogen removal, the reduction in the removal of reactive species can be traced to the reduced presence of immobile active microbial biomass in heterogeneous domains. In contrast, the contribution of the mobile active biomass in heterogeneous domains remains largely the same as that in homogeneous domains. This indicates that the mobile microbial abundance detected in groundwater samples must be used with care as a proxy for effective microbial activity and nutrient cycling (also confirmed by Alfreider et al., 1997, Murphy et al., 1997, Griebler et al., 2002, and Grösbacher et al., 2018, as mentioned earlier).

\subsection{Indicators to evaluate impact of spatial heterogeneity on biomass and redox regimes}

In this study, we explored three different flow regimes, representing Péclet $(\mathrm{Pe})$ numbers varying over an order of magnitude. The Damköhler number of the varying components of the system (derived from the observed mass removals and breakthrough times) varies over 4 orders of magnitude (Fig. S6a) in the considered scenarios.

There is substantial overlap in $D a$ across all the flow regimes; a given reactive species has different $D a$ in the different heterogeneous domains in each flow regime. However, spatial heterogeneity impacts the removal of each reactive species in the flow regimes differently. This is further evidenced in the significant improvement of the model AIC (Table S1) when the reactive species is included as a fixed effect in conjunction with the flow regime. While this approach helps us to generate a predictive understanding of system behaviour, it is specific to the reactive species and flow regimes concerned. For a scalable approach to modelling and predicting nutrient cycles at larger scales, it is therefore useful to consider proxy indicators that may assist in generalizing this expression.

Noting that the impact of spatial heterogeneity on removal of nitrogen in the medium flow regime and of DO and TOC in the fast flow regime is the same given the same reduction in breakthrough time (Fig. S7), we consider the impact of spatial heterogeneity in the context of $D a$ or $\log _{10} D a$, thus providing an opportunity to disentangle reactive species and flow regimes in terms of non-dimensional numbers (Fig. 5). The impact of spatial heterogeneity on nutrient cycling varies with the value of $\log _{10} \mathrm{Da}$ (Fig. 5). For values higher than 0.5 , the impact is negligible. For $\log _{10} D a<-1$, spatial heterogeneity results in an increased removal of nutrients from 
the domain. This is in part due to the negligible removal of the corresponding nutrients in the base case (specifically, nitrogen in the fast flow regime, refer to Sects. 3.3 and 4.1). Even a marginal increase in the relevant microbial activity results in a remarkably high impact on the removal of the corresponding nutrient when compared to the base case. As discussed above, for the fast flow regime oxic conditions with aerobic activity are found along the entire homogeneous domain. Since most nitrogen removal processes are suppressed by elevated DO concentrations, the formation of a sub-oxic zone exhibiting anaerobic activity in low flow regions of the heterogeneous domains is the only chance for these nitrogen removal processes to take place in the fast flow scenario. The observed increase in mass removal with heterogeneity is thus to some extent an artefact that may not represent a general trend. While heterogeneity does have an impact on nitrogen removal in the fast flow regime, even after increased removal, the $\log _{10} D a$ value remains below -1 , indicating low absolute activity and removal.

For regimes where $\log _{10} D a>0.5$, spatial heterogeneity has a limited impact on the ability of the system to remove reactive species. But the removal of reactive species decreases with the reduction in breakthrough time for $-1<\log _{10} D a<$ 0.5. To explore the cause of this, we compared the trend of removal of reactive species in first-order rates (Fig. S8) and zero-order rates with reduced residence times with the simulation results for varying values of $\log _{10} D a$. The mean of $\log _{10} D a$ in this regime was -0.3 with a standard deviation of 0.3. So, we approximated the analytical solution for varying values of $\log _{10} D a$ (Fig. S8). With increasing $\log _{10} D a$ (between 0 and 0.5), the root mean squared error (RMSE) between the analytical solution for a first-order reaction and the simulation results decreases. Additionally, the data points lie in between the solutions for first-order and zero-order kinetics, as would be the case for Monod kinetics in the case of reduced residence times. Consequently, the impact of spatial heterogeneity on regimes with $0<\log _{10} D a<0.5$ may be described on the bases of reducing residence time alone, and the results do not allow us to determine if additional heterogeneity effects on removal take place. For regimes where $-1<\log _{10} D a<0$, first-order kinetics may be substituted with zero-order kinetics. Additionally, the impact on mass removal of reactive species in this domain is lower than estimated from the analytical solution. Therefore, while mass removal of reactive species reduces with reducing breakthrough times, it does not follow Monod kinetics, which implies that heterogeneity has a different impact on removal than changing only the residence time. In fact, the impact of spatial heterogeneity on mass removal is lower than that predicted by reducing residence time alone. For a quantitative assessment we proposed linear regression metrics to estimate mass removal resulting from reducing residence times. At the same time, we observed that the dramatic increase in mass removal for regimes $\log _{10} D a<-1$ is not attributable to a shorter residence time but is due to heterogeneous con- ditions providing niches to the relevant microbial species to become active. Therefore, we conclude that spatial heterogeneity may result in changed nutrient dynamics. The regression model links the impact of heterogeneity to variables which can be estimated in field studies. Furthermore, this helps to categorize reaction regimes to consider if spatial heterogeneity is of significance. For high $\log _{10} D a$ values, spatial heterogeneity is not of significance. For extremely low $\log _{10} D a$ values, spatial heterogeneity resulted for the used model domains in a high impact on removal rates with respect to the homogeneous base cases. However, this might be an artefact of the used domain size, and the absolute removal values are still low. Thus, heterogeneity effects may

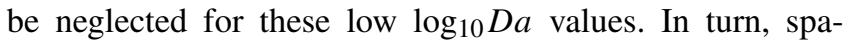
tial heterogeneity is significant for medium range $\log _{10} D a$ values $\left(-1<\log _{10} D a<0.5\right)$. For these values, the highest heterogeneity-induced reductions in mass removal were observed and can be well described by the linear regression model.

We expect advection-dominated systems to be impacted by spatial heterogeneity because spatial heterogeneity had a higher impact on the transport profiles in these systems. These are typically systems that are shallow, less compacted (in the case of alluvial sediments), or fractured rock systems. Furthermore, the shallow subsurface also receives bioavailable and reactive organic matter with the incoming water which enables a relatively high microbial activity. In contrast, in the deep subsurface microbial activity is lower and rather relies more often on inputs from the matrix material, which is ubiquitous and does not rely on transport for access to nutrients or energy gradients. It must be noted that this generic description of dominant processes serves to give examples for reactive systems for the purpose of our discussion and may vary from site to site depending on specific site characteristics. We expect additional studies exploring the impact of varying concentrations of chemical species and parameters relevant to these ecosystems or subject sites to add to the evidence generated by our study that the impact of spatial heterogeneity on sub-surficial reactive systems may be predicted using field-estimated indicators such as breakthrough time, $P e$, and $D a$.

\section{Summary and conclusions}

In this study, we investigated the impact of spatial heterogeneity on biomass persistence, distribution, and nutrient cycling at the sub-metre scale in the subsurface. When considering spatial heterogeneity, a combination of variance and anisotropy of the hydraulic conductivity was considered when evaluating the transport regime, which may be further interpreted as a reduction of solute residence time in the domain. The flow regime was found to play an influential role in the average behaviour of the domain. Not only does the total microbial biomass vary with the flow regime, but the 
contribution of different fractions of microbial biomass (between active or inactive, mobile or immobile) is also different based on the flow regime. Spatial heterogeneity also impacts the different fractions of microbial biomass differently. This has a cumulative impact on nutrient cycling in the subsurface. The activity of the microbial species in the domain is governed by the spatial heterogeneity as it influences the distribution of nutrients and energy sources. We found that several microbial species that are conventionally accepted to occupy mutually exclusive niches may co-exist in the subsurface in close vicinity. This further demonstrates that the occurrence of oxic systems does not preclude the existence of anaerobic species in the same zone as heterogeneity leads to the formation of sub-oxic regions with anaerobic activity within an oxic zone exhibiting predominantly aerobic activity. Since modellers and experimentalists do not conventionally resolve these small-scale heterogeneities, the accuracy of the prediction of biogeochemical cycles at the larger scale suffers.

Depending on the reaction and flow regime of the domain, the impact of spatial heterogeneity on mass removal of reactive species can be quantified as a linear function of the breakthrough time. We propose the use of the Damköhler number to identify the appropriate parameters of this function. Simulations that neglect or aggregate microbially mediated dynamics in spatially heterogeneous media may overestimate reactive species removal by as much as 2 times. This factor can be predicted using readily observable data that inform Damköhler numbers and residence times using a linear function of residence time. We propose using this scaling factor to account for heterogeneity in regional-scale simulations for the accurate prediction of microbial-mediated reactive species dynamics in groundwater.

\section{Appendix A: Biochemical reaction network}

\section{A1 Reactive species}

1. Chemical compounds:

- dissolved organic carbon (DOC)

- particulate organic carbon (POC)

- oxygen $\left(\mathrm{O}_{2}\right)$

- nitrate $\left(\mathrm{NO}_{3}\right)$

- sulfate $\left(\mathrm{SO}_{4}\right)$

- ammonium $\left(\mathrm{NH}_{4}\right)$

2. Microbial species:

- aerobic DOC degraders $\left(\mathrm{BO}_{2}\right)$

- nitrate reducers $\left(\mathrm{BNO}_{3}\right)$

- sulfate reducers $\left(\mathrm{BSO}_{4}\right)$

- ammonia oxidizers $\left(\mathrm{BNH}_{4}\right)$
For each microbial species, we considered different subpopulations: active bacteria able to grow and to perform biogeochemical reactions, inactive bacteria, immobile bacteria attached to the solid matrix, and mobile bacteria moving with the flowing water. In combination this leads to four subpopulations for each microbial species $X$ : active immobile $\left(X_{\mathrm{a}, \mathrm{s}}\right)$, active mobile $\left(X_{\mathrm{a}, \mathrm{w}}\right)$, inactive immobile $\left(X_{\mathrm{i}, \mathrm{s}}\right)$, and inactive mobile $\left(X_{\mathrm{i}, \mathrm{w}}\right)$.

\section{A2 Biogeochemical reactions}

1. Aerobic respiration:

$$
\mathrm{CH}_{2} \mathrm{O}+\mathrm{O}_{2} \rightarrow \mathrm{HCO}_{3}^{-}+\mathrm{H}^{+}
$$

2. Nitrate reduction:

$$
\begin{gathered}
\mathrm{CH}_{2} \mathrm{O}+0.8 \mathrm{NO}_{3}^{-}+0.8 \mathrm{H}^{+} \rightarrow \mathrm{HCO}_{3}^{-} \\
+0.4 \mathrm{~N}_{2}+0.4 \mathrm{H}_{2} \mathrm{O}+\mathrm{H}^{+}
\end{gathered}
$$

3. Sulfate reduction:

$$
\begin{aligned}
\mathrm{CH}_{2} \mathrm{O} & +0.5 \mathrm{SO}_{4}^{2-}+\mathrm{H}^{+} \rightarrow \mathrm{HCO}_{3}^{-} \\
& +0.5 \mathrm{HS}^{-}+1.5 \mathrm{H}^{+}
\end{aligned}
$$

4. Ammonia oxidation:

$$
0.5 \mathrm{NH}_{4}^{+}+\mathrm{O}_{2} \rightarrow 0.5 \mathrm{NO}_{3}^{-}+0.5 \mathrm{H}_{2} \mathrm{O}+\mathrm{H}^{+}
$$

5. Hydrolysis of POC:

$$
\mathrm{C}_{10} \mathrm{H}_{7} \mathrm{O}_{2} \mathrm{~N}+8 \mathrm{H}_{2} \mathrm{O}+\mathrm{H}^{+} \rightarrow 10 \mathrm{CH}_{2} \mathrm{O}+\mathrm{NH}_{4}^{+}
$$

\section{A3 Rate expressions}

\section{A3.1 Microbial respiration}

We used modified Monod-type expressions for microbially driven reactions. The term Kxx depends on the specific group of microorganisms performing the degradation process (Table A1):

1. Aerobic respiration:

$$
r=\left(\frac{\mathrm{O}_{2} \min (1-\mathrm{Kxx})}{e^{\frac{\mathrm{Kxx}}{\mathrm{st}}}+1}\right) \times\left(\mathrm{BO}_{2 \mathrm{a}, \mathrm{s}}+\mathrm{BO}_{2 \mathrm{a}, \mathrm{w}}\right),
$$

2. Nitrate reduction:

$$
r=\left(\frac{\mathrm{NO}_{3} \min (1-\mathrm{Kxx})}{e^{\frac{\mathrm{Kxx}}{\mathrm{st}}+1}}\right) \times\left(\mathrm{BNO}_{3 \mathrm{a}, \mathrm{s}}+\mathrm{BNO}_{3 \mathrm{a}, \mathrm{w}}\right)
$$

3. Sulfate reduction:

$$
r=\left(\frac{\mathrm{SO}_{4} \min (1-\mathrm{Kxx})}{e^{\frac{\mathrm{Kx}}{\mathrm{st}}}+1}\right) \times\left(\mathrm{BSO}_{4 \mathrm{a}, \mathrm{s}}+\mathrm{BSO}_{4 \mathrm{a}, \mathrm{w}}\right)
$$

4. Ammonia oxidation:

$$
r=\left(\frac{\mathrm{NH}_{4} \min (1-\mathrm{Kxx})}{e^{\frac{\mathrm{Kxx}}{\mathrm{st}}}+1}\right) \times\left(\mathrm{BNH}_{4 \mathrm{a}, \mathrm{s}}+\mathrm{BNH}_{4 \mathrm{a}, \mathrm{w}}\right)
$$




\section{A3.2 Microbial growth}

Growth processes (i.e. formation of biomass carbon) are linked to rates of microbially driven reactions using a constant yield factor with an additional dependency on the concentration of ammonium and its availability for uptake. For the latter, we considered a fixed ratio between carbon (DOC) and nitrogen $\left(\mathrm{NH}_{4}\right)$ uptake. As mentioned above, the term Kxx depends on the specific group of microorganisms performing the degradation process (Table A1).

1. Dependency on ammonium:

$$
\mathrm{NH}_{4} \text { limit }=\frac{1}{e^{\frac{\text { amming- }-\mathrm{NH}_{4}}{\mathrm{st} \times a \operatorname{mming}}}+1}
$$

2. Active aerobic DOC degraders:

$$
r=\mathrm{NH}_{4} \text { limit } \times\left(\frac{\mathrm{O}_{2} \min (1-\mathrm{Kxx})}{e^{\frac{\mathrm{Kxx}}{\mathrm{st}}}+1}\right) \times Y o \times \mathrm{BO}_{2 \mathrm{a}, \mathrm{x}}
$$

with $a$ indicating active biomass, and $x$ indicating the location of the bacteria; either $x=s$ for attached bacteria or $x=w$ for mobile bacteria.

3. Active nitrate reducers:

$$
r=\mathrm{NH}_{4} \operatorname{limit} \times\left(\frac{\mathrm{NO}_{3} \min (1-\mathrm{Kxx})}{e^{\frac{\mathrm{Kxx}}{\mathrm{st}}}+1}\right) \times Y n \times \mathrm{BNO}_{3 \mathrm{a}, \mathrm{x}}
$$

4. Active sulfate reducers:

$$
r=\mathrm{NH}_{4} \operatorname{limit} \times\left(\frac{\mathrm{SO}_{4} \min (1-\mathrm{Kxx})}{e^{\frac{\mathrm{Kxx}}{\mathrm{st}}}+1}\right) \times Y s \times \mathrm{BSO}_{4 \mathrm{a}, \mathrm{x}}
$$

5. Active ammonia oxidizers:

$$
r=\mathrm{NH}_{4} \operatorname{limit} \times\left(\frac{\mathrm{NH}_{4} \min (1-\mathrm{Kxx})}{e^{\frac{K \mathrm{xx}}{\mathrm{st}}}+1}\right) \times Y a \times \mathrm{BNH}_{4 \mathrm{a}, \mathrm{x}}
$$

\section{A3.3 Processes governing the location of the microbes}

1. The mobilization of immobilized bacteria $(\mathrm{Bxx})$ into the fluid medium (i.e. the transfer of attached bacteria into mobile bacteria) is adapted from Rittman and McCarty (2001) assuming additionally that high total attached biomasses lead to higher detachment rates (adapted from Clément et al., 1997):

$$
\begin{aligned}
& r=\mathrm{kl} \times(\mathrm{vq} 0 \times \operatorname{vpor} 0)^{0.58} \times \mathrm{Bxx}
\end{aligned}
$$

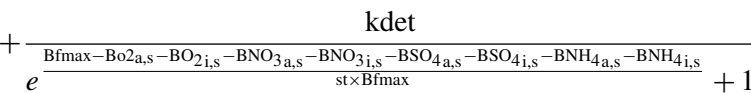

$$
\begin{aligned}
& \times \mathrm{Bxx}
\end{aligned}
$$

2. Immobilization or reattachment: attachment rates of mobile bacteria Byy also depend on the total concentration of attached biomass:

$r=\mathrm{katt}$

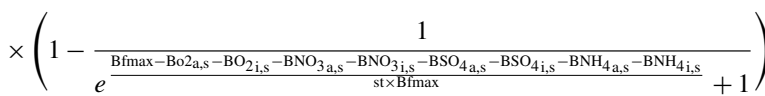
$\times$ Byy

\section{A3.4 Processes governing the activity states of microbes}

1. Deactivation or dormancy: deactivation rates of active bacteria (i.e. conversion of active (mobile or attached) into inactive or inactive (mobile or attached) bacteria) in unfavourable substrate conditions are expressed following Stolpovsky et al. (2011).

$r=\operatorname{kdeac} \times \operatorname{Bxx} \times\left(1-\frac{1}{e^{\frac{\mathrm{Kxx}}{\mathrm{st}}}+1}\right)$,

with the term Kxx depending on the bacterial species Byy and its substrate source (see Table A1).

2. Reactivation: in analogy to the deactivation rates, reactivation rates are expressed as follows:

$r=\operatorname{kreac} \times \operatorname{Byy} \times \frac{1}{e^{\frac{K x x}{s t}}+1}$,

with the term Kxx depending on the bacterial species as described in Table A1.

3. Mortality: mortality rates follow a first-order dependency on biomass concentration.

$r=\mathrm{km} \times$ fdorm $\times \mathrm{Bxx}$

For active bacteria fdorm $=1$, and for inactive bacteria fdorm $=0.1$. Dead bacterial biomass is added to the particulate organic matter (POM) pool. 
Table A1. Expressions controlling respiration, growth, dormancy, and reactivation of microbial species.

\begin{tabular}{|c|c|c|c|c|}
\hline \multirow[t]{2}{*}{ Notation } & \multicolumn{4}{|c|}{ Descriptors } \\
\hline & Aerobic degraders & Nitrate reducers & Sulfate reducers & Ammonia oxidizers \\
\hline $\mathrm{Bxx}$ & $\mathrm{BO}_{2 \mathrm{a}, \mathrm{s}}$ and $\mathrm{BO}_{2 \mathrm{a}, \mathrm{w}}$ & $\mathrm{BNO}_{3 \mathrm{a}, \mathrm{s}}$ and $\mathrm{BNO}_{3 \mathrm{a}, \mathrm{w}}$ & $\mathrm{BSO}_{4 \mathrm{a}, \mathrm{s}}$ and $\mathrm{BSO}_{4 \mathrm{a}, \mathrm{w}}$ & $\mathrm{BNH}_{4 \mathrm{a}, \mathrm{s}}$ and $\mathrm{BNH}_{4 \mathrm{a}, \mathrm{w}}$ \\
\hline Byy & $\mathrm{BO}_{2 \mathrm{i}, \mathrm{s}}$ and $\mathrm{BO}_{2 \mathrm{i}, \mathrm{w}}$ & $\mathrm{BNO}_{3 \mathrm{i}, \mathrm{s}}$ and $\mathrm{BNO}_{3 \mathrm{i}, \mathrm{w}}$ & $\mathrm{BSO}_{4 \mathrm{a}, \mathrm{s}}$ and $\mathrm{BSO}_{4 \mathrm{i}, \mathrm{w}}$ & $\mathrm{BNH}_{4 \mathrm{a}, \mathrm{s}}$ and $\mathrm{BNH}_{4 \mathrm{i}, \mathrm{w}}$ \\
\hline $\mathrm{Kxx}$ & $\begin{array}{l}1-\operatorname{kmax} 1 \\
\times\left(\frac{\mathrm{DOC}}{\mathrm{ksodoc} 1+\mathrm{DOC}}\right) \\
\times\left(\frac{\mathrm{O}_{2}}{\mathrm{ksox} 1+\mathrm{O}_{2}}\right) / \mathrm{O}_{2} \mathrm{~min}\end{array}$ & $\begin{array}{l}1-\mathrm{kmax} 2 \\
\times\left(\frac{\mathrm{DOC}}{\mathrm{ksndoc}+\mathrm{DOC}}\right) \\
\times\left(\frac{\mathrm{kindox}}{\text { kindox }+\mathrm{O}_{2}}\right) \\
\times\left(\frac{\mathrm{NO}_{3}}{\mathrm{ksno}_{3}+\mathrm{NO}_{3}}\right) / \mathrm{NO}_{3} \min \end{array}$ & $\begin{array}{l}1-\mathrm{kmax} \\
\times\left(\frac{\mathrm{DOC}}{\mathrm{kssdoc}+\mathrm{DOC}}\right) \\
\times\left(\frac{\mathrm{SO}_{4}}{\mathrm{ksso}+\mathrm{SO}_{4}}\right) \\
\times\left(\frac{\mathrm{kindox}}{\text { kindox }+\mathrm{O}_{2}}\right) \\
\times\left(\frac{\mathrm{kinno3}}{\mathrm{kinno3}+\mathrm{NO}_{3}}\right) / \mathrm{SO}_{4} \mathrm{~min}\end{array}$ & $\begin{array}{l}1-\mathrm{kmax} \\
\times\left(\frac{\mathrm{NH}_{4}}{\mathrm{ksamm} \mathrm{NH}_{4}}\right) \\
\times\left(\frac{\mathrm{O}_{2}}{\mathrm{ksox}+\mathrm{O}_{2}}\right) / \mathrm{NH}_{4} \mathrm{~min}\end{array}$ \\
\hline
\end{tabular}

\section{A3.5 Miscellaneous processes}

1. Hydrolysis of POC is described by first-order rate kinetics:

$$
r=\mathrm{kpd} \times \mathrm{POC}
$$

2. Background autotrophic microbial growth is dependent on the presence of ammonium:

$$
r=\mathrm{NH}_{4} \text { limit } \times \operatorname{kmax} 5 \times\left(\frac{\mathrm{NH}_{4}}{\mathrm{ksamm}+\mathrm{NH}_{4}}\right)
$$

\section{A4 Parameters}

\section{A4.1 Biogeochemical reaction network parameters}




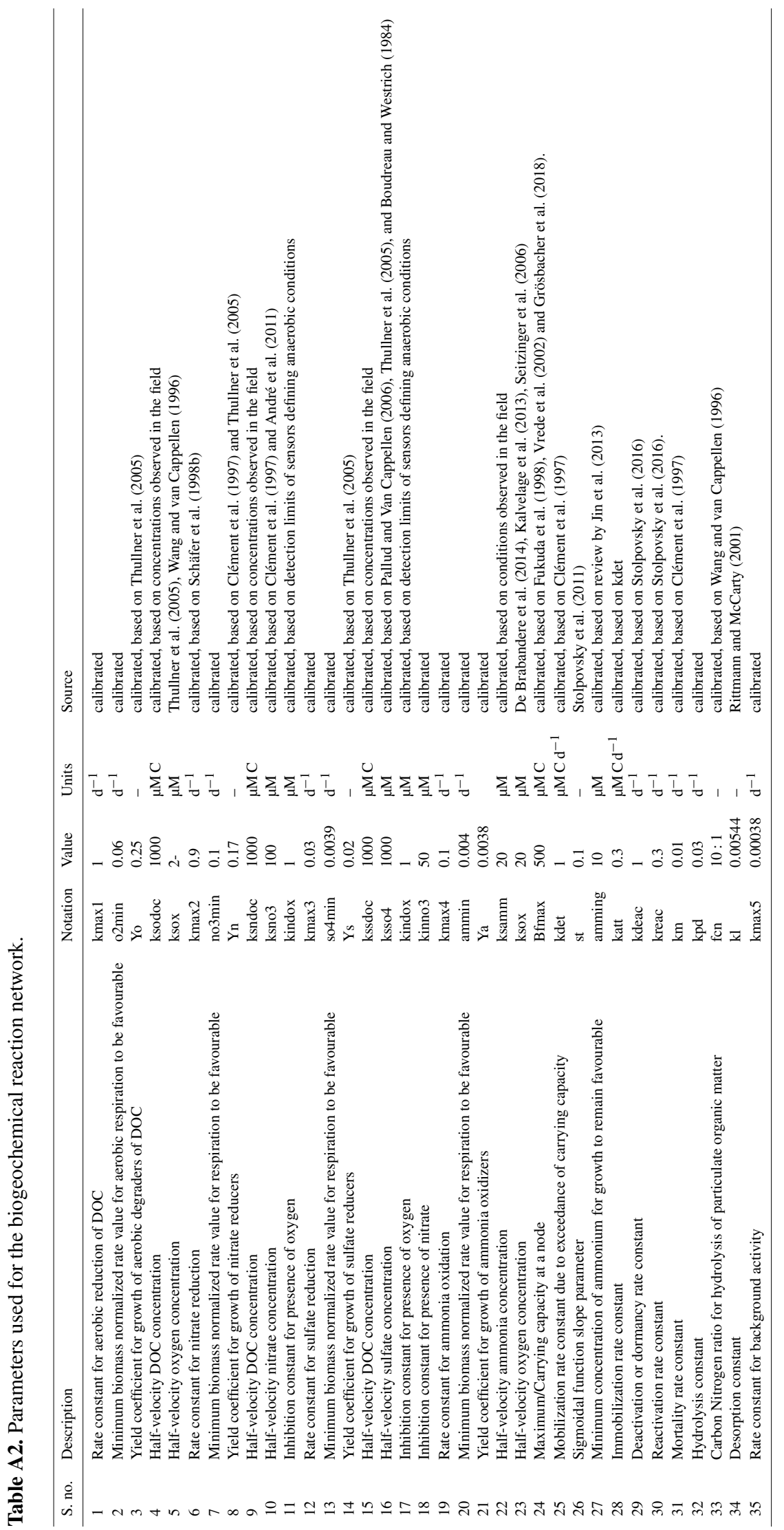




\section{A4.2 Transport boundary conditions}

Table A3. Flow and transport parameterization and boundary conditions for all domains in all three flow regimes. The boundary condition for the reactive species was a Dirichlet boundary condition (fixed concentration) at the inlet of the domain.

\begin{tabular}{ll}
\hline Property (units) & Value \\
\hline Porosity $(-)$ & 0.2 \\
Density (matrix, $\mathrm{kg} \mathrm{m}^{-3}$ ) & 1500 \\
Density (groundwater, $\mathrm{kg} \mathrm{m}^{-3}$ ) & 1000 \\
\hline \multicolumn{2}{l}{ Boundary conditions for chemical and microbial species at the inlet of the domain } \\
\hline POM $(\mu \mathrm{MC})$ & 5 \\
DOC $(\mu \mathrm{MC})$ & 800 \\
DO $(\mu \mathrm{M})$ & 250 \\
Nitrate $(\mu \mathrm{M})$ & 250 \\
Ammonium $(\mu \mathrm{M})$ & 60 \\
Sulfate $(\mu \mathrm{M})$ & 1500 \\
Bx,w $(\mu \mathrm{MC})$ & 2 \\
\hline
\end{tabular}

Code availability. OGS5 is available in an online repository (https://doi.org/10.5281/zenodo.4617988, Khurana et al., 2021). The input files for all simulated scenarios are available in the same repository. In addition, we also provide the Maple worksheet and resulting BRNS dynamically linked library that is required to run the simulations in OGS-BRNS at this link. We also provide the Python scripts used for processing the raw simulation results and for generating graphics in this publication at this link. The processed datasets are also available in this repository.

Data availability. We provide the raw simulation results in this repository on Zenodo (https://doi.org/10.5281/zenodo.4288721, Khurana et al., 2020) along with processed data files.

Supplement. The supplement related to this article is available online at: https://doi.org/10.5194/bg-19-665-2022-supplement.

Author contributions. SK conceptualized the reaction network, defined the scenarios to be simulated, executed the simulations, analysed the results, and drafted the manuscript. AH, FH, and MT provided guidance and technical support. MT defined and supervised the study. All co-authors contributed to the interpretation of the results and editing the manuscript.

Competing interests. The contact author has declared that neither they nor their co-authors have any competing interests.

Disclaimer. Publisher's note: Copernicus Publications remains neutral with regard to jurisdictional claims in published maps and institutional affiliations.
Acknowledgements. This study is part of the Collaborative Research Centre AquaDiva of the Friedrich Schiller University Jena, funded by the Deutsche Forschungsgemeinschaft (DFG, German Research Foundation) - SFB 1076 - project number 218627073. The authors would like to thank Thomas Kalbacher for his valuable support in setting up the scenarios in OpenGeoSys and Tino Rödiger for providing useful insight into the recharge dynamics at and geology of the subject site. The authors also thank the handling editor, Tom J. Battin, and the reviewers, Meret Aeppli and two anonymous reviewers, for their invaluable comments that helped us improve the manuscript further.

Financial support. This research has been supported by the Deutsche Forschungsgemeinschaft (grant no. 218627073).

The article processing charges for this open-access publication were covered by the Helmholtz Centre for Environmental Research - UFZ.

Review statement. This paper was edited by Tom J. Battin and reviewed by Meret Aeppli and two anonymous referees.

\section{References}

Aguilera, D. R., Jourabchi, P., Spiteri, C., and Regnier, P.: A knowledge-based reactive transport approach for the simulation of biogeochemical dynamics in Earth systems, Geochem. Geophys. Geosys., 6, Q07012, https://doi.org/10.1029/2004gc000899, 2005.

Alewell, C., Paul, S., Lischeid, G., Küsel, K., and Gehre, M.: Characterizing the redox status in three different forested wetlands 
with geochemical data, Environ. Sci. Technol., 40, 7609-7615, https://doi.org/10.1021/es061018y, 2006.

Alfreider, A., Krossbacher, M., and Psenner, R.: Groundwater samples do not reflect bacterial densities and activity in subsurface systems, Water Res., 31, 832-840, 1997.

Anneser, B., Einsiedl, F., Meckenstock, R. U., Richters, L., Wisotzky, F., and Griebler, C.: High-resolution monitoring of biogeochemical gradients in a tar oilcontaminated aquifer, Appl. Geochem., 23, 1715-1730, https://doi.org/10.1016/j.apgeochem.2008.02.003, 2008.

Arora, B., Spycher, N. F., Steefel, C. I., Molins, S., Bill, M., Conrad, M. E., Dong, W., Faybishenko, B., Tokunaga, T. K., Wan, J., Williams, K. H., and Yabusaki, S. B.: Influence of hydrological, biogeochemical and temperature transients on subsurface carbon fluxes in a flood plain environment, Biogeochemistry, 127, 367396, https://doi.org/10.1007/s10533-016-0186-8, 2016.

Báez-Cazull, S., McGuire, J. T., Cozzarelli, I. M., Raymond, A., and Welsh, L.: Centimeter-scale characterization of biogeochemical gradients at a wetland-aquifer interface using capillary electrophoresis, Appl. Geochem., 22, 2664-2683, https://doi.org/10.1016/j.apgeochem.2007.06.003, 2007.

Ballarini, E., Beyer, C., Bauer, R. D., Griebler, C., and Bauer, S.: Model based evaluation of a contaminant plume development under aerobic and anaerobic conditions in $2 \mathrm{D}$ bench-scale tank experiments, Biodegradation, 25, 351-371, https://doi.org/10.1007/s10532-013-9665-y, 2014.

Benk, S. A., Yan, L., Lehmann, R., Roth, V.-N., Schwab, V. F., Totsche, K. U., Küsel, K., and Gleixner, G.: Fueling Diversity in the Subsurface: Composition and Age of Dissolved Organic Matter in the Critical Zone, Front. Earth Sci., 7, 296, https://doi.org/10.3389/feart.2019.00296, 2019.

Centler, F., Shao, H., De Biase, C., Park, C.-H., Regnier, P., Kolditz, O., and Thullner, M.: GeoSysBRNS - A flexible multidimensional reactive transport model for simulating biogeochemical subsurface processes, Comp. Geosci., 36, 397-405, https://doi.org/10.1016/j.cageo.2009.06.009, 2010.

Cole, J. J., Prairie, Y. T., Caraco, N. F., McDowell, W. H., Tranvik, L. J., Striegl, R. G., Duarte, C. M., Kortelainen, P., Downing, J. A., Middelburg, J. J., and Melack, J.: Plumbing the Global Carbon Cycle: Integrating Inland Waters into the Terrestrial Carbon Budget, Ecosystems, 10, 172-185, https://doi.org/10.1007/s10021-006-9013-8, 2007.

Couradeau, E., Sasse, J., Goudeau, D., Nath, N., Hazen, T. C., Bowen, B. P., Chakraborty, R., Malmstrom, R. R., and Northen, T. R.: Probing the active fraction of soil microbiomes using BONCAT-FACS, Nat. Commun., 10, 2770, https://doi.org/10.1038/s41467-019-10542-0, 2019.

De Brabandere, L., Canfield, D. E., Dalsgaard, T., Friederich, G. E., Revsbech, N. P., Ulloa, O., and Thamdrup, B.: Vertical partitioning of nitrogen-loss processes across the oxic-anoxic interface of an oceanic oxygen minimum zone, Environ Microbiol., 16, 3041-3054, https://doi.org/10.1111/1462-2920.12255, 2014.

Desbarats, A. J. and Bachu, S.: Geostatistical analysis of aquifer heterogeneity from the core scale to the basin scale: A case study, Water Resour. Res., 30, 673-684, 1994.

Ding, D.: Transport of bacteria in aquifer sediment: experiments and modeling, Hydrogeol. J., 18, 669-679, https://doi.org/10.1007/s10040-009-0559-3, 2009.
Dwivedi, D., Arora, B., Steefel, C. I., Dafflon, B., and Versteeg, R.: Hot Spots and Hot Moments of Nitrogen in a Riparian Corridor, Water Resour. Res., 54, 205-222, https://doi.org/10.1002/2017wr022346, 2018.

Eckert, D., Kürzinger, P., Bauer, R., Griebler, C., and Cirpka, O. A.: Fringe-controlled biodegradation under dynamic conditions: Quasi 2-D flow-through experiments and reactivetransport modeling, J. Contaminant Hydrol., 172, 100-111, https://doi.org/10.1016/j.jconhyd.2014.11.003, 2015.

Edery, Y., Porta, G. M., Guadagnini, A., Scher, H., and Berkowitz, B.: Characterization of Bimolecular Reactive Transport in Heterogeneous Porous Media, Transport in Porous Media, 115, 291310, https://doi.org/10.1007/s11242-016-0684-0, 2016.

Franklin, S., Vasilas, B., and Jin, Y.: More than Meets the Dye: Evaluating Preferential Flow Paths as Microbial Hotspots, Vadose Zone J., 18, 190024, https://doi.org/10.2136/vzj2019.03.0024, 2019.

Fukuda, R., Ogawa, H., Nagata, T., and Koike, I.: Direct determination of carbon and nitrogen contents of natural bacterial assemblages in marine environments, Appl. Environ. Microb., 64, 3352-3358, https://doi.org/10.1128/aem.64.9.33523358.1998, 1998.

Gharasoo, M., Centler, F., Regnier, P., Harms, H., and Thullner, M.: A reactive transport modeling approach to simulate biogeochemical processes in pore structures with porescale heterogeneities, Environ. Model. Softw., 30, 102-114, https://doi.org/10.1016/j.envsoft.2011.10.010, 2012.

Giardino, J. R. and Houser, C.: Chapter 20 - A Summary and Future Direction of the Principles and Dynamics of the Critical Zone, in: Developments in Earth Surface Processes, edited by: Giardino, J. R. and Houser, C., Elsevier, 19, 619-628, https://doi.org/10.1016/B978-0-444-63369-9.00020-3, 2015.

Griebler, C., Mindl, B., Slezak, D., and Geiger-Kaiser, M.: Distribution patterns of attached and suspended bacteria in pristine and contaminated shallow aquifers studied with an in situ sediment exposure microcosm, Aquat. Microb. Ecol., 28, 117-129, 2002.

Griebler, C. and Lueders, T.: Microbial biodiversity in groundwater ecosystems, Freshwater Biol., 54, 649-677, https://doi.org/10.1111/j.1365-2427.2008.02013.x, 2009.

Grösbacher, M., Eckert, D., Cirpka, O. A., and Griebler, C.: Contaminant concentration versus flow velocity: drivers of biodegradation and microbial growth in groundwater model systems, Biodegradation, 29, 211-232, https://doi.org/10.1007/s10532018-9824-2, 2018.

Gu, A. Z., Pedros, P. B., Kristiansen, A., Onnis-Hayden, A., and Schramm, A.: Nitrifying community analysis in a single submerged attached-growth bioreactor for treatment of highammonia waste stream, Water Environ. Res., 79, 2510-2518, https://doi.org/10.2175/106143007x254566, 2007.

Harden, J. W., O’Neill, K. P., Trumbore, S. E., Veldhuis, H., and Stocks, B. J.: Moss and soil contributions to the annual net carbon flux of a maturing boreal forest, J. Geophys. Res.-Atmos., 102, 28805-28816, 1997.

Heath, R. C.: Basic groundwater-hydrology, U.S. Geological Survey, U.S. Geological Survey Water-Supply Paper, 81 pp., 1983.

Heße, F., Harms, H., Attinger, S., and Thullner, M.: Linear exchange model for the description of mass transfer limited bioavailability at the pore scale, Environ. Sci. Technol., 44, 2064-2071, 2010. 
Heße, F., Prykhodko, V., Schlüter, S., and Attinger, S.: Generating random fields with a truncated power-law variogram: A comparison of several numerical methods, Environ. Model. Softw., 55, 32-48, https://doi.org/10.1016/j.envsoft.2014.01.013, 2014.

Hofmann, R. and Griebler, C.: DOM and bacterial growth efficiency in oligotrophic groundwater: absence of priming and colimitation by organic carbon and phosphorus, Aquat. Microb. Ecol., 81, 55-71, https://doi.org/10.3354/ame01862, 2018.

Hofmann, R., Uhl, J., Hertkorn, N., and Griebler, C.: Linkage Between Dissolved Organic Matter Transformation, Bacterial Carbon Production, and Diversity in a Shallow Oligotrophic Aquifer: Results From Flow-Through Sediment Microcosm Experiments, Front. Microbiol., 11, 543567, https://doi.org/10.3389/fmicb.2020.543567, 2020.

Holm, P. E., Nielsen, P. H., Albrechtsen, H. J., and Christensen, T. H.: Importance of unattached bacteria and bacteria attached to sediment in determining potentials for degradation of xenobiotic organic contaminants in an aerobic aquifer, Appl. Environ. Microb., 58, 3020-3026, https://doi.org/10.1128/aem.58.9.30203026.1992, 1992.

Holt, M. S.: Sources of chemical contaminants and routes into the freshwater environment, Food Chem. Toxicol., 38, 21-27, https://doi.org/10.1016/S0278-6915(99)00136-2, 2000.

Hunter, K. S., Wang, Y., and Cappellen, P. V.: Kinetic modeling of microbially-driven redox chemistry of subsurface environments: coupling transport, microbial metabolism and geochemistry, J. Hydrol., 209, 53-80, 1998.

ISO 17289: 2014-Water quality - Determination of dissolved oxygen - Optical sensor method, International Organization for Standardization, Geneva, Switzerland, 14 pp., 2014.

Jing, M., Heße, F., Kumar, R., Wang, W., Fischer, T., Walther, M., Zink, M., Zech, A., Samaniego, L., Kolditz, O., and Attinger, S.: Improved regional-scale groundwater representation by the coupling of the mesoscale Hydrologic Model (mHM v5.7) to the groundwater model OpenGeoSys (OGS), Geosci. Model Dev., 11, 1989-2007, https://doi.org/10.5194/gmd-111989-2018, 2018.

Jung, H. and Meile, C.: Upscaling of microbially driven first-order reactions in heterogeneous porous media, J. Contam. Hydrol., 224, 103483, https://doi.org/10.1016/j.jconhyd.2019.04.006, 2019.

Kalvelage, T., Lavik, G., Lam, P., Contreras, S., Arteaga, L., Löscher, C. R., Oschlies, A., Paulmier, A., Stramma, L., and Kuypers, M. M. M.: Nitrogen cycling driven by organic matter export in the South Pacific oxygen minimum zone, Nat. Geosci., 6, 228-234, https://doi.org/10.1038/ngeo1739, 2013.

Khurana, S., Heße, F., Hildebrandt, A., and Thullner, M.: Simulation Results: Influence of spatial heterogeneity on microbial redox dynamics in the subsurface, Zenodo [data set], https://doi.org/10.5281/zenodo.4288721, 2020.

Khurana, S., Heße, F., Hildebrandt, A., and Thullner, M.: Spatial heterogeneity impact on microbial redox dynamics (Version v1.0.0), Zenodo [code], https://doi.org/10.5281/zenodo.4617988, 2021.

Kim, K. H., Yun, S. T., Choi, B. Y., Chae, G. T., Joo, Y., Kim, K., and Kim, H. S.: Hydrochemical and multivariate statistical interpretations of spatial controls of nitrate concentrations in a shallow alluvial aquifer around oxbow lakes (Os- ong area, central Korea), J. Contam. Hydrol., 107, 114-127, https://doi.org/10.1016/j.jconhyd.2009.04.007, 2009.

Kim, K. H., Michael, H. A., Field, E. K., and Ullman, W. J.: Hydrologic Shifts Create Complex Transient Distributions of Particulate Organic Carbon and Biogeochemical Responses in Beach Aquifers, J. Geophys. Res.-Biogeo., 124, 3024-3038, https://doi.org/10.1029/2019jg005114, 2019.

King, E. L., Tuncay, K., Ortoleva, P., and Meile, C.: Modeling biogeochemical dynamics in porous media: Practical considerations of pore scale variability, reaction networks, and microbial population dynamics in a sandy aquifer, J. Contam. Hydrol., 112, 130-140, https://doi.org/10.1016/j.jconhyd.2009.12.002, 2010.

Kohlhepp, B., Lehmann, R., Seeber, P., Küsel, K., Trumbore, S. E., and Totsche, K. U.: Aquifer configuration and geostructural links control the groundwater quality in thinbedded carbonate-siliciclastic alternations of the Hainich CZE, central Germany, Hydrol. Earth Syst. Sci., 21, 6091-6116, https://doi.org/10.5194/hess-21-6091-2017, 2017.

Kolditz, O., Bauer, S., Bilke, L., Böttcher, N., Delfs, J. O., Fischer, T., Görke, U. J., Kalbacher, T., Kosakowski, G., McDermott, C. I., Park, C. H., Radu, F., Rink, K., Shao, H., Shao, H. B., Sun, F., Sun, Y. Y., Singh, A. K., Taron, J., Walther, M., Wang, W., Watanabe, N., Wu, Y., Xie, M., Xu, W., and Zehner, B.: OpenGeoSys: an open-source initiative for numerical simulation of thermo-hydro-mechanical/chemical (THM/C) processes in porous media, Environ. Earth Sci., 67, 589-599, https://doi.org/10.1007/s12665-012-1546-x, 2012.

Küsel, K., Totsche, K. U., Trumbore, S. E., Lehmann, R., Steinhäuser, C., and Herrmann, M.: How Deep Can Surface Signals Be Traced in the Critical Zone?, Merging Biodiversity with Biogeochemistry Research in a Central German Muschelkalk Landscape, Front. Earth Sci., 4, 32, https://doi.org/10.3389/feart.2016.00032, 2016.

Lehmann, K., Lehmann, R., and Totsche, K. U.: Eventdriven dynamics of the total mobile inventory in undisturbed soil account for significant fluxes of particulate organic carbon, Sci. Tot. Environ., 756, 143774, https://doi.org/10.1016/j.scitotenv.2020.143774, 2021.

Lennon, J. T. and Jones, S. E.: Microbial seed banks: the ecological and evolutionary implications of dormancy, Nat. Rev. Microbiol., 9, 119-130, https://doi.org/10.1038/nrmicro2504, 2011.

Liao, Z. and Cirpka, O. A.: Shape-free inference of hyporheic traveltime distributions from synthetic conservative and "smart" tracer tests in streams, Water Resour. Res., 47, W07510, https://doi.org/10.1029/2010wr009927, 2011.

Liu, Y., Lawrence, C. R., Winnick, M. J., Hsu, H. T., Maher, K., and Druhan, J. L.: Modeling Transient Soil Moisture Limitations on Microbial Carbon Respiration, J. Geophys. Res.-Biogeo., 124, 2222-2247, https://doi.org/10.1029/2018jg004628, 2019.

Lohmann, P., Benk, S., Gleixner, G., Potthast, K., Michalzik, B., Jehmlich, N., and Bergen, M. V.: Seasonal Patterns of Dominant Microbes Involved in Central Nutrient Cycles in the Subsurface, Microorganisms, 8, 1694, https://doi.org/10.3390/microorganisms8111694, 2020.

Manzoni, S. and Porporato, A.: Soil carbon and nitrogen mineralization: Theory and models across scales, Soil Biol. Biochem., 41, 1355-1379, https://doi.org/10.1016/j.soilbio.2009.02.031, 2009. 
McGuire, J. T., Smith, E. W., Long, D. T., Hyndman, D. W., Haack, S. K., Klug, M. J., and Velbel, M. A.: Temporal variations in parameters reflecting terminal-electron-accepting processes in an aquifer contaminated with waste fuel and chlorinated solvents, Chem. Geol., 169, 471-485, https://doi.org/10.1016/S00092541(00)00223-0, 2000

McMahon, S. and Parnell, J.: Weighing the deep continental biosphere, FEMS Microbiol. Ecol., 87, 113-120, https://doi.org/10.1111/1574-6941.12196, 2014.

Meile, C. and Tuncay, K.: Scale dependence of reaction rates in porous media, Adv. Water Res., 29, 62-71, https://doi.org/10.1016/j.advwatres.2005.05.007, 2006.

Molins, S., Trebotich, D., Yang, L., Ajo-Franklin, J. B., Ligocki, T. J., Shen, C., and Steefel, C. I.: Pore-scale controls on calcite dissolution rates from flow-through laboratory and numerical experiments, Environ Sci. Technol., 48, 7453-7460, https://doi.org/10.1021/es5013438, 2014.

Müller, S., Schüler, L., Zech, A., and Heße, F.: GSTools v1.3: A toolbox for geostatistical modelling in Python, Geosci. Model Dev. Discuss. [preprint], https://doi.org/10.5194/gmd-2021-301, in review, 2021.

Müller, S., Zech, A., and Heße, F.: ogs5py: A Python-API for the OpenGeoSys 5 Scientific Modeling Package, Groundwater, 59, 117-122, https://doi.org/10.1111/gwat.13017, 2021.

Murphy, E. M., Ginn, T. R., Chilakapati, A., Resch, C. T., Phillips, J. L., Wietsma, T. W., and Spadoni, C. M.: The influence of physical heterogeneity on microbial degradation and distribution in porous media, Water Resour. Res., 33, 1087-1103, https://doi.org/10.1029/96wr03851, 1997.

Opitz, S., Küsel, K., Spott, O., Totsche, K. U., and Herrmann, M.: Oxygen availability and distance to surface environments determine community composition and abundance of ammoniaoxidizing prokaroytes in two superimposed pristine limestone aquifers in the Hainich region, Germany, FEMS Microb. Ecol., 90, 39-53, https://doi.org/10.1111/1574-6941.12370, 2014.

Painter, S. L.: Multiscale Framework for Modeling Multicomponent Reactive Transport in Stream Corridors, Water Resour. Res., 54, 7216-7230, https://doi.org/10.1029/2018wr022831, 2018.

Powell, R. M. and Puls, R. W.: Passive sampling of groundwater monitoring wells without purging: multilevel well chemistry and tracer disappearance, J. Contam. Hydrol., 12, 51-77, https://doi.org/10.1016/0169-7722(93)90015-K, 1993.

Prommer, H., Barry, D. A., and Davis, G. B.: A one-dimensional reactive multi-component transport model for biodegradation of petroleum hydrocarbons in groundwater, Environ. Model. Softw., 14, 213-223, 1999.

Regnier, P., O'Kane, J. P., Steefel, C. I., and vanderborght, J. P.: Modeling complex multi-component reactive-transport systems: towards a simulation environment based on the concept of a Knowledge Base, Appl. Math. Model., 26, 913-927, 2002.

Ronen, D., Magaritz, M., Gvirtzman, H., and Garner, W.: Microscale chemical heterogeneity in groundwater, J. Hydrol., 92, 173-178, https://doi.org/10.1016/0022-1694(87)90094-1, 1987.

Sanz-Prat, A., Lu, C., Finkel, M., and Cirpka, O. A.: On the validity of travel-time based nonlinear bioreactive transport models in steady-state flow, J. Contam. Hydrol., 175, 26-43, https://doi.org/10.1016/j.jconhyd.2015.02.003, 2015.
Sanz-Prat, A., Lu, C., Finkel, M., and Cirpka, O. A.: Using travel times to simulate multi-dimensional bioreactive transport in time-periodic flows, J. Contam. Hydrol., 187, 1-17, https://doi.org/10.1016/j.jconhyd.2016.01.005, 2016.

Schäfer, D., Schäfer, W., and Kinzelbach, W.: Simulation of reactive processes related to biodegradation in aquifers 2. Model application to a column study on organic carbon degradation, J. Contam. Hydrol., 31, 187-209, 1998a.

Schäfer, D., Schäfer, W., and Kinzelbach, W.: Simulation of reactive processes related to biodegradation in aquifers. 1. Structure of the three-dimensional reactive transport model, J. Contam. Hydrol., 31, 167-186, https://doi.org/10.1016/S0169-7722(97)00060-0, 1998 b.

Schlesinger, W. H. and Andrews, J. A.: Soil respiration and the global carbon cycle, Biogeochemistry, 48, 7-20, 2000.

Schwab, V. F., Herrmann, M., Roth, V.-N., Gleixner, G., Lehmann, R., Pohnert, G., Trumbore, S., Küsel, K., and Totsche, K. U.: Functional diversity of microbial communities in pristine aquifers inferred by PLFA- and sequencing-based approaches, Biogeosciences, 14, 2697-2714, https://doi.org/10.5194/bg-142697-2017, 2017.

Seitzinger, S., Harrison, J. A., J.K. Böhlke, Bouwman, A. F., Lowrance, R., Peterson, B., Tobias, C., and Drecht, G. V.: Denitrification across landscapes and waterscapes: A Synthesis, Ecol. Appl., 16, 2064-2090, 2006.

Smith, R. L., Howes, B. L., and Duff, J. H.: Denitrification in nitrate-contaminated groundwater: Occurrence in steep vertical geochemical gradients, Geochim. Cosmochim. Ac., 55, 18151825, https://doi.org/10.1016/0016-7037(91)90026-2, 1991.

Smith, H. J., Zelaya, A. J., De León, K. B., Chakraborty, R., Elias, D. A., Hazen, T. C., Arkin, A. P., Cunningham, A. B., and Fields, M. W.: Impact of hydrologic boundaries on microbial planktonic and biofilm communities in shallow terrestrial subsurface environments, FEMS Microb. Ecol., 94, fiy191, https://doi.org/10.1093/femsec/fiy191, 2018.

Stolpovsky, K., Martinez-Lavanchy, P., Heipieper, H. J., Van Cappellen, P., and Thullner, M.: Incorporating dormancy in dynamic microbial community models, Ecol. Model., 222, 3092-3102, https://doi.org/10.1016/j.ecolmodel.2011.07.006, 2011.

Thullner, M., Van Cappellen, P., and Regnier, P.: Modeling the impact of microbial activity on redox dynamics in porous media, Geochim. Cosmochim. Ac., 69, 5005-5019, https://doi.org/10.1016/j.gca.2005.04.026, 2005.

Thullner, M., Regnier, P., and Van Cappellen, P.: Modeling Microbially Induced Carbon Degradation in Redox-Stratified Subsurface Environments: Concepts and Open Questions, Geomicrobiol. J., 24, 139-155, https://doi.org/10.1080/01490450701459275, 2007.

Thullner, M. and Regnier, P.: Microbial Controls on the Biogeochemical Dynamics in the Subsurface, Rev. Mineral. Geochem., 85, 265-302, https://doi.org/10.2138/rmg.2019.85.9, 2019.

Tufenkji, N.: Modeling microbial transport in porous media: Traditional approaches and recent developments, Adv. Water Res., 30, 1455-1469, https://doi.org/10.1016/j.advwatres.2006.05.014, 2007.

Turcke, M. A. and Kueper, B. H.: Geostatistical analysis of the Borden aquifer hydraulic conductivity field, 178, 223-240, 1996. 
van Leeuwen, F. X. R.: Safe Drinking Water: the Toxicologist's Approach, Food Chem. Toxicol., 38, 51-58, https://doi.org/10.1016/S0278-6915(99)00140-4, 2000.

van Rossum, G. and Drake Jr., F. L.: The Python Language Reference Manual (version 3.2), edited by: Drake Jr, F. L., Network Theory Ltd, 120 pp., 2006.

Vogel, L. E., Pot, V., Makowski, D., Garnier, P., and Baveye, P. C.: To what extent do uncertainty and sensitivity analyses help unravel the influence of microscale physical and biological drivers in soil carbon dynamics models?, Ecol. Model., 383, 10-22, https://doi.org/10.1016/j.ecolmodel.2018.05.007, 2018.

Vrede, K., Heldal, M., Norland, S., and Bratbak, G.: Elemental composition $(\mathrm{C}, \mathrm{N}, \mathrm{P})$ and cell volume of exponentially growing and nutrient-limited bacterioplankton, Appl. Environ. Microb., 68, 2965-2971, https://doi.org/10.1128/AEM.68.6.29652971.2002, 2002.

Waldron, P. J., Wu, L., Van Nostrand, J. D., Schadt, C. W., He, Z., Watson, D. B., Jardine, P. M., Palumbo, A. V., Hazen, T. C., and Zhou, J.: Functional gene array-based analysis of microbial community structure in groundwaters with a gradient of contaminant levels, Environ. Sci. Technol., 43, 3529-3534, https://doi.org/10.1021/es803423p, 2009.

Welhan, J. A. and Reed, M. F.: Geostatistical analysis of regional hydraulic conductivity variations in the Snake River Plain aquifer, eastern Idaho, GSA Bull., 109, 855-868, 1997.
Wirtz, K. W.: Control of biogeochemical cycling by mobility and metabolic strategies of microbes in the sediments: an integrated model study, FEMS Microb. Ecol., 46, 295-306, https://doi.org/10.1016/s0168-6496(03)00196-x, 2003.

Yabusaki, S. B., Wilkins, M. J., Fang, Y., Williams, K. H., Arora, B., Bargar, J., Beller, H. R., Bouskill, N. J., Brodie, E. L., Christensen, J. N., Conrad, M. E., Danczak, R. E., King, E., Soltanian, M., R., Spycher, N. F., Steefel, C. I., Tokunaga, T. K., Versteeg, R., Waichler, S. T., and Wainwright, H. M.: Water Table Dynamics and Biogeochemical Cycling in a Shallow, VariablySaturated Floodplain, Environ. Sci. Technol., 51, 3307-3317, https://doi.org/10.1021/acs.est.6b04873, 2017a.

Yabusaki, S. B., Wilkins, M. J., Fang, Y., Williams, K. H., Arora, B., Bargar, J., Beller, H. R., Bouskill, N. J., Brodie, E. L., Christensen, J. N., Conrad, M. E., Danczak, R. E., King, E., Soltanian, M. R., Spycher, N. F., Steefel, C. I., Tokunaga, T. K., Versteeg, R., Waichler, S. R., and Wainwright, H. M.: Water Table Dynamics and Biogeochemical Cycling in a Shallow, VariablySaturated Floodplain, Environ. Sci. Technol., 51, 3307-3317, https://doi.org/10.1021/acs.est.6b04873, 2017b.

Zhou, Y., Kellermann, C., and Griebler, C.: Spatio-temporal patterns of microbial communities in a hydrologically dynamic pristine aquifer, FEMS Microb. Ecol., 81, 230-242, https://doi.org/10.1111/j.1574-6941.2012.01371.x, 2012. 